\title{
Type I collagen aging impairs discoidin domain receptor 2-mediated tumor cell growth suppression
}

\author{
Charles Saby ${ }^{1}$, Emilie Buache ${ }^{1}$, Sylvie Brassart-Pasco ${ }^{2}$, Hassan El Btaouri², Marie- \\ Pierre Courageot ${ }^{3}$, Laurence Van Gulick ${ }^{1}$, Roselyne Garnotel ${ }^{2}$, Pierre Jeannesson ${ }^{1}$ \\ and Hamid Morjani ${ }^{1}$ \\ ${ }^{1}$ Centre National de la Recherche Scientifique (CNRS), Unité Mixte de Recherche (UMR) Matrice Extracellulaire et Dynamique \\ Cellulaire, Université de Reims Champagne-Ardenne, Unité de Formation et de Recherche (UFR) Pharmacie, Reims, France \\ ${ }^{2}$ Centre National de la Recherche Scientifique (CNRS), Unité Mixte de Recherche (UMR) Matrice Extracellulaire et Dynamique \\ Cellulaire, Université de Reims Champagne-Ardenne, Unité de Formation et de Recherche (UFR) Médecine, Reims, France \\ ${ }^{3}$ Centre National de la Recherche Scientifique (CNRS), Unité Mixte de Recherche (UMR) Matrice Extracellulaire et Dynamique \\ Cellulaire, Université de Reims Champagne-Ardenne, Unité de Formation et de Recherche (UFR) Sciences Exactes et \\ Naturelles, Reims, France
}

Correspondence to: Hamid Morjani, email: hamid.morjani@univ-reims.fr

Keywords: type I collagen, aging, cancer, discoidin domain receptor 2, cell proliferation, Gerotarget

Received: July 16, $2015 \quad$ Accepted: April 10, $2016 \quad$ Published: April 18, 2016

\section{ABSTRACT}

Tumor cells are confronted to a type I collagen rich environment which regulates cell proliferation and invasion. Biological aging has been associated with structural changes of type I collagen. Here, we address the effect of collagen aging on cell proliferation in a three-dimensional context (3D).

We provide evidence for an inhibitory effect of adult collagen, but not of the old one, on proliferation of human fibrosarcoma HT-1080 cells. This effect involves both the activation of the tyrosine kinase Discoidin Domain Receptor 2 (DDR2) and the tyrosine phosphatase SHP-2. DDR2 and SHP-2 were less activated in old collagen. DDR2 inhibition decreased SHP-2 phosphorylation in adult collagen and increased cell proliferation to a level similar to that observed in old collagen.

In the presence of old collagen, a high level of JAK2 and ERK1/2 phosphorylation was observed while expression of the cell cycle negative regulator $\mathrm{p} 21^{\text {cip } 1}$ was decreased. Inhibition of DDR2 kinase function also led to an increase in ERK1/2

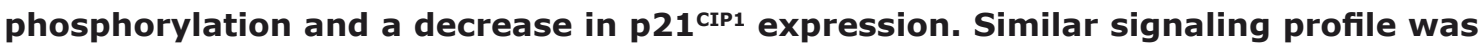
observed when DDR2 was inhibited in adult collagen. Altogether, these data suggest that biological collagen aging could increase tumor cell proliferation by reducing the activation of the key matrix sensor DDR2.

\section{INTRODUCTION}

Recent studies have emphasized the importance of bidirectional communication between neoplastic cells and their microenvironment in modulating tumor progression and metastasis, which represent the main uncontrolled problem in cancer therapeutics and the main cause of patient death [1]. The supporting players originating from surrounding normal tissue or from circulation include stromal fibroblasts, immune cells, vascular cells and the extracellular matrix (ECM) that can contribute both positive and negative signals to the tumor cells. Because of their pivotal role in tumor development and growth, the tumor microenvironment (TME) components are considered as challenging and attractive therapeutic targets.

During cancer initiation and progression, such a complex crosstalk involves dynamic interactions between tumor cells and ECM proteins, well-known to drive fundamental cellular functions including proliferation, differentiation, and motility. These interactions take place during the first steps of primary tumor growth, at the invasive edge for metastatic dissemination and during the initiation of secondary outgrowth in metastatic niches.

The main component of the interacting ECM proteins is fibrillar type I collagen that forms the mechanical backbone of interstitial tissues and constitutes up to $90 \%$ protein content [2]. Thus, this component 
is a privileged partner that can influence tumor cell proliferation. Type I collagen can be used as a preintravasation microenvironment and can be involved in the initiation of secondary outgrowth in metastatic niches.

Interestingly, due to its particular longevity with an estimated half-life of 15 years in humans, this key matrix protein appears as a preferential target for modifications during chronological and pathological aging, such as glycation that leads to Advanced Glycation End products formation (AGEs) [3]. These AGEs that interact with a specific receptor, AGEs receptor (RAGE), have been shown to play a role in tumor progression $[4,5]$. Enzymatic modifications also induce an increase in collagen fibers cross-linking and consequently an alteration in type I collagen fibrillar properties [6]. Metalloproteinases have also been shown to alter type I collagen integrity [7]. These enzymatic modifications are able to impact tumor progression [8, 9].

At the cellular level, different transmembrane type I collagen receptors have been identified: integrins, the most studied receptors [10] and Discoidin Domain Receptors DDR1 and DDR2, the least explored ones [11]. In collagen molecules, the specific consensus sequence motifs GFOGER [12] are recognized by the heterodimeric integrins $\alpha 1 \beta 1$ and $\alpha 2 \beta 1$. DDR1 and DDR2 differ from the integrins in that they belong to the tyrosine kinase receptor (RTK) superfamily. DDR1 and DDR2 recognize GVMGFO motifs [13]. Unlike classical growth factor activated RTKs, such as the EGFR receptors which display rapid and transient activation [14], DDR1 and DDR2 are unique in that they exhibit delayed and sustained phosphorylation upon binding to collagen [15].

In the present study, we evaluated the influence of adult and aged three-dimensional (3D) collagen matrices on the proliferation of human HT-1080 fibrosarcoma cells. It is important to note that $3 \mathrm{D}$ collagen matrices are in vitro culture models closest to in vivo microenvironment. A significantly high cell proliferation rate was observed in old collagen compared to the adult one. This led us to investigate which actor among the receptors cited above, RAGE, integrins or DDRs, might be responsible for the effects observed. The present study demonstrates that DDR2 - as a key component of type I collagen-cell interaction and signaling - leads to differential regulation of cell proliferation between adult and old $3 \mathrm{D}$ collagen matrices.

\section{RESULTS}

\section{Effect of aging on type I collagen properties}

Type I collagen was extracted from tail tendons of rats aged 2 months (adult) and 2 years (old) as described in the material and methods section. For each extraction experiment, ten animals were used for each age regardless of sex. Data previously obtained have shown that proliferation rate of HT-1080 cells was similar in collagen from males and females (data not shown). Then, collagens have been characterized according to the properties associated with the process of aging. First we analyzed advanced glycation endproduct (AGE) load which is commonly increased in aged-tissue, especially in long life proteins such as collagen [16, 17]. AGE content was assessed by detecting total AGEs quantified by fluorescence spectroscopy, and specific AGEs $\mathrm{N} \varepsilon-$ (Carboxymethyl) lysine (CML), and pentosidine by LC/MS/MS. As expected, age-dependent analyses showed that the level of fluorescing AGEs, CML and pentosidine, increased in collagen prepared from old rats compared to adult ones (Figure 1A-1C). Enzymatic cross-link content, known to be modified during aging [17], was then analyzed. As shown in Figure 1D, old collagen exhibits a higher concentration of the cross-links hydroxylysylpyridinoline and lysylpyrodinoline compared to the adult one. Finally, we analyzed the electrophoretic properties of collagens by SDS-PAGE method. For this, 5 $\mu \mathrm{g}$ of either adult or old rat type I collagen were analyzed on $5 \%$ polyacrylamide gels under reducing conditions. As can be seen in Figure 1E, both collagens exhibited the two characteristic chains $\alpha 1$ and $\alpha 2$ of native type I collagen. For old collagen, both chains migrated slower than in the case of adult collagen indicating a higher density of these chains in old collagen. The intensity of both chain bands was lower in old collagen than in the adult one. This could be due to an increased amount of higher molecular weight polymers in old collagen [18].

\section{Effect of aging on cell proliferation}

We then examined whether contact with adult vs. old collagen gels differentially influenced the proliferative responses of the HT-1080 cells. For this, HT-1080 cells were seeded in adult and old collagen 3D matrices and cell growth was evaluated up to 7 days of culture. As shown in Figure 2A, HT-1080 cells in old collagen exhibited a significantly higher proliferation rate as early as day 4 of culture $(p<0.01)$. This difference in cell proliferation markedly increased up to day 7 ( $p<0.001)$. We then compared the cell proliferation after 5 days of culture, in a $3 \mathrm{D}$ collagen matrix vs. 2D collagen coating. As shown in Figure $2 \mathrm{~B}$ and $2 \mathrm{C}$, the differential cell proliferation was only observed in $3 \mathrm{D}$. In order to demonstrate the generality of this finding, we analyzed proliferation of A204 sarcoma cells in adult and old collagen 3D matrices. As shown in the supplementary data 1A, A204 cells exhibited also a significantly higher proliferation rate in old collagen when compared to the adult one. Taken together, these data indicate that collagen aging promotes HT-1080 cell proliferation, and that this process only occurs in a $3 \mathrm{D}$ environment. 
A

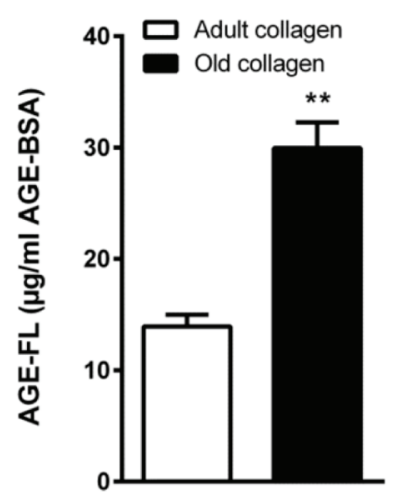

C

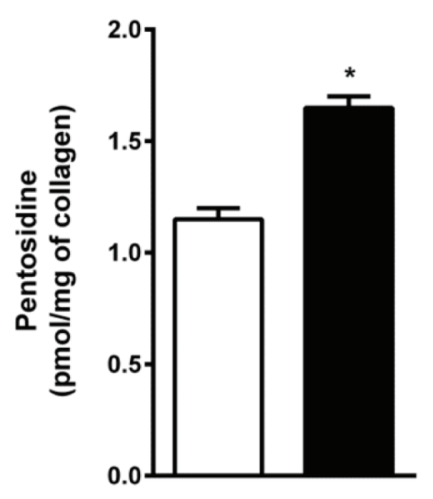

B

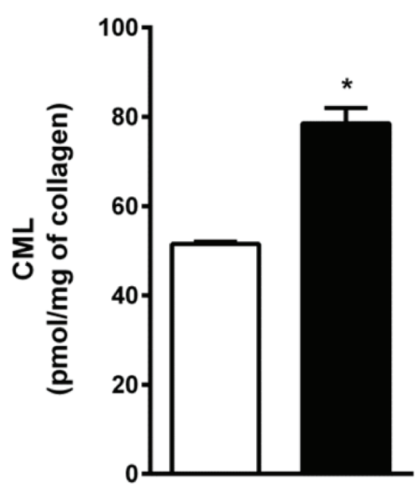

$\mathrm{D}$

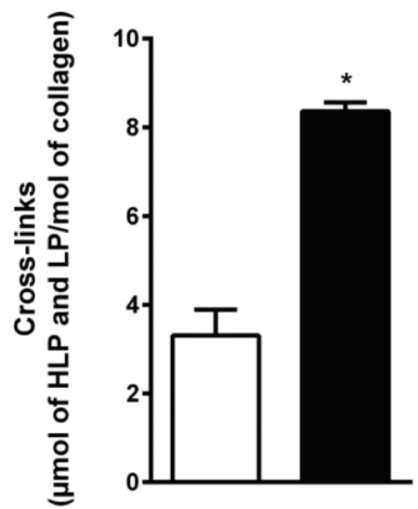

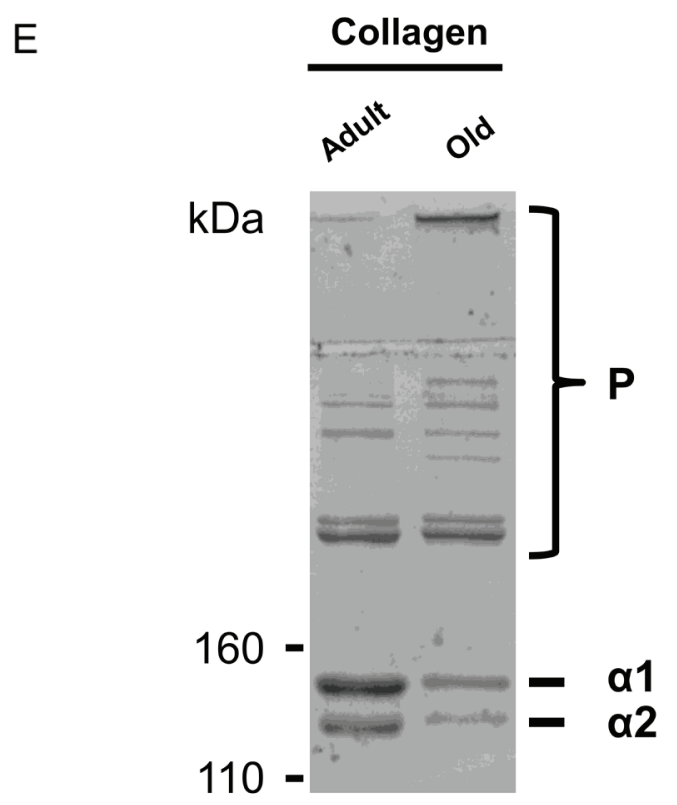

Figure 1: Characterization of collagens. A. Spectrofluorimetric analysis was performed on adult and old collagen to detect AGEsspecific fluorescence expressed as $\mu \mathrm{g} / \mathrm{ml}$. B. CML and C. Pentosidine were quantified by LC-MS/MS and expressed as pmol/mg of collagen. D. Cross-link content was measured by the quantification of hydroxylysylpyridinoline (HLP) and lysylpyrodinoline (LP) by ion exchange chromatography and expressed as $\mu \mathrm{mol}$ (LHP and LP)/mol of collagen. E. SDS-PAGE of collagen samples, $5 \mu \mathrm{g}$ of either adult or old rat type I collagens were analyzed on 5\% polyacrylamide gels under reducing conditions. Collagen chains ( $\alpha 1$ and $\alpha 2)$, and highermolecular-weight polymers (P) are indicated. Values represent the mean \pm S.E.M. of three independent experiments $\left({ }^{*} p<0.05,{ }^{* *} p<0.01\right)$. 
A

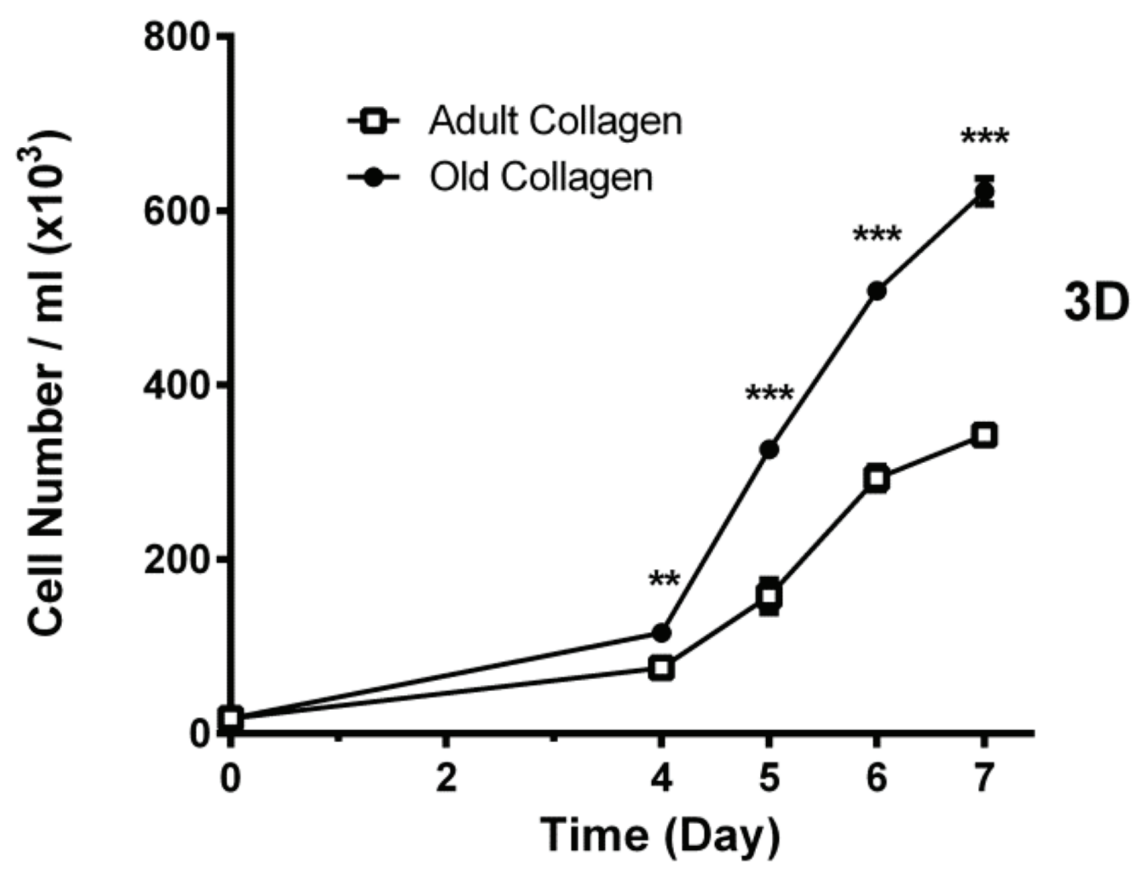

B

C
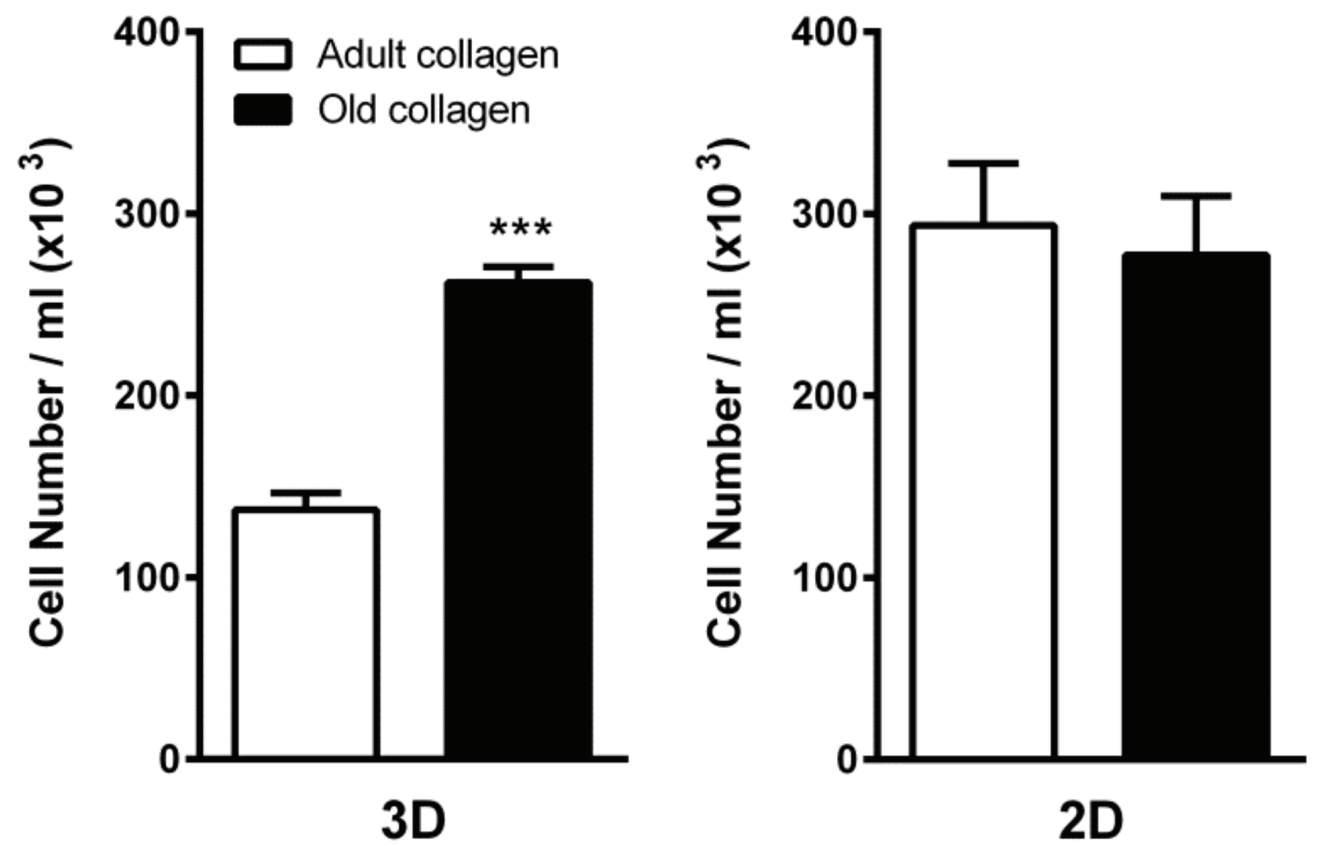

Figure 2: Effect of collagen aging on HT-1080 cell proliferation in 2D and 3D matrices. A. HT-1080 cells were seeded in adult and old type I collagen 3D matrices at a density of $1.5 \times 10^{4} \mathrm{cells} / \mathrm{ml}$. After 4, 5, 6 and 7 days of culture, cell density was evaluated by phase contrast microscopy. B. HT-1080 cells were seeded in adult and old type I collagen 3D matrices at a density of $1.5 \times 10^{4}$ cells $/ \mathrm{ml}$. After 5 days of culture, cell density was evaluated. C. HT-1080 cells were seeded on adult and old type I collagen 2D coating at a density of $1.5 \times 10^{4}$ cells $/ \mathrm{ml}$. After 5 days of culture, cell density was evaluated by phase contrast microscopy. Values represent the mean \pm S.E.M. of three independent experiments $(* * p<0.01, * * * p<0.001)$. 


\section{AGE receptor is not involved in the increased cell} proliferation

We studied the possible involvement of AGEs and their receptor RAGE in the regulation of cell proliferation. Indeed, AGE/RAGE axis has been shown to modulate tumor cell growth [19]. First we analyzed the expression of the RAGE mRNA using q-PCR. As shown in Figure 3A, RAGE was poorly expressed in HT-1080 cells. In
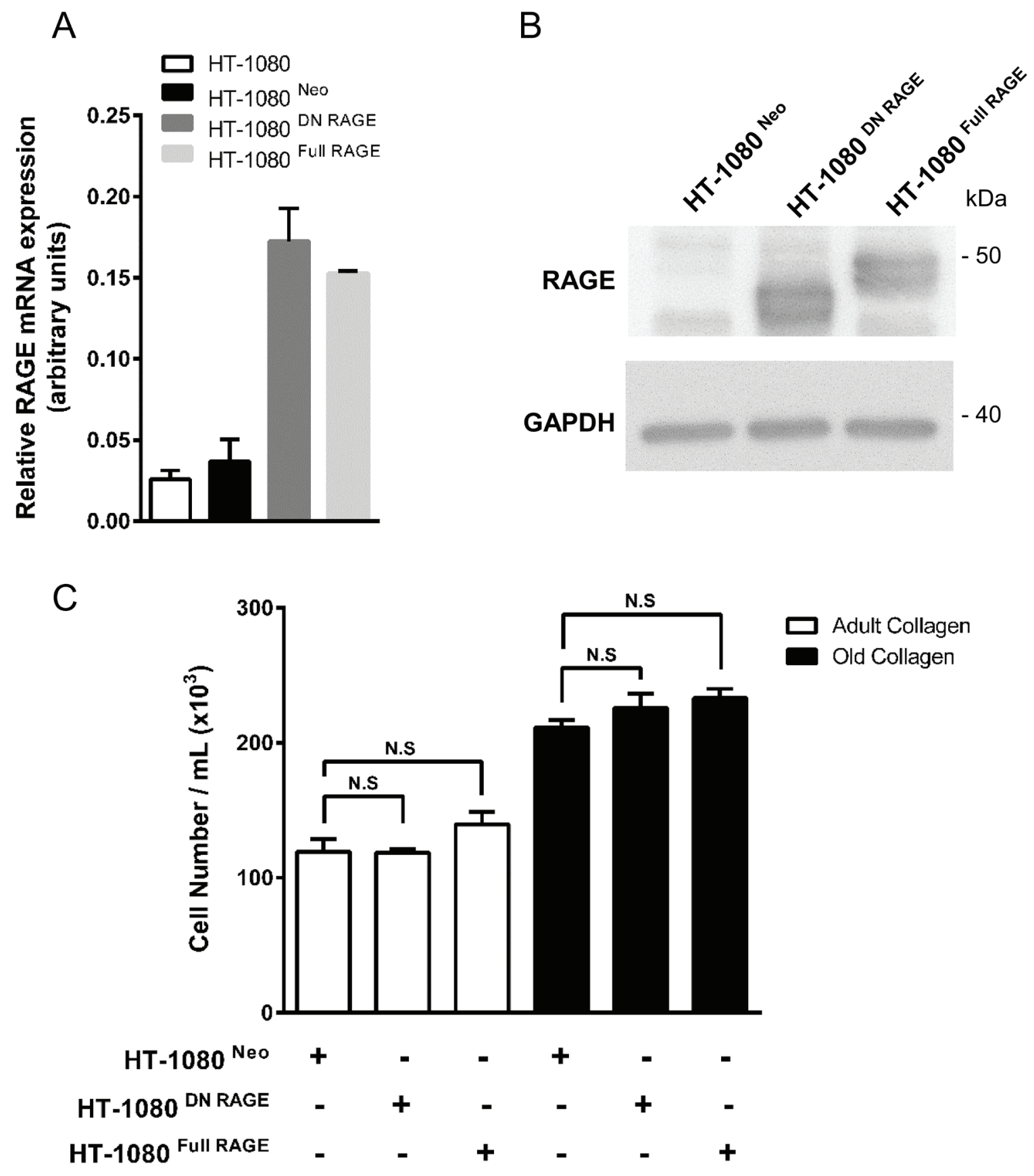

Figure 3: RAGE expression in parental and RAGE-transfected HT-1080 cells, and effect of collagen aging on cell proliferation. Parental HT-1080 and HT-1080 cells stably transfected with empty vector (HT-1080 ${ }^{\mathrm{Neo}}$ ), human full length RAGE (HT-

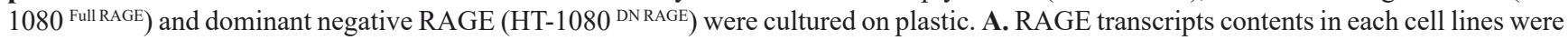
evaluated by real-time quantitative polymerase chain reaction. B. RAGE protein expression was analyzed by western blot. Glyceraldehyde 3-phosphate deshydrogenase (GAPDH) was used as a loading control. C. Parental and transfected HT-1080 cells were seeded in adult and old type I collagen 3D matrices at a density of $1.5 \times 10^{4}$ cells $/ \mathrm{ml}$. After 5 days of culture, cell density was evaluated by phase contrast microscopy. Data shown are representative of three independent experiments (N.S. $=$ not significant). 

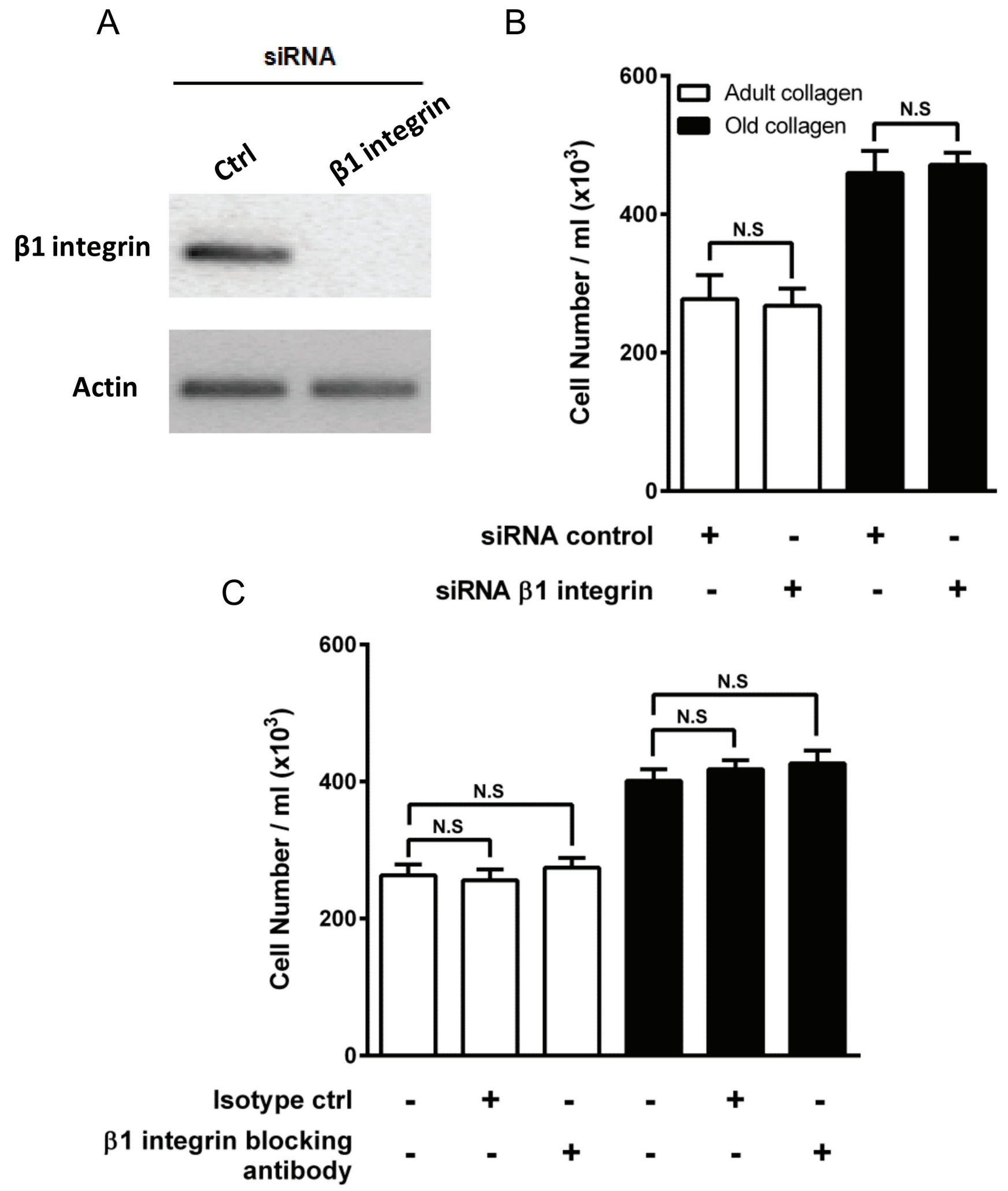

Figure 4: Effect of $\boldsymbol{\beta} 1$ integrin inhibition on HT-1080 cell proliferation. A. HT-1080 cells were transfected with control siRNA (Ctrl) or $\beta 1$ integrin siRNA. $\beta 1$ integrin expression was analyzed by RT-PCR. Actin was used as a control. HT-1080 cells were seeded in adult and old type I collagen 3D matrices at a density of $5 \times 10^{4} \mathrm{cells} / \mathrm{ml}$, with or without $\mathbf{B}$. siRNA directed against $\beta 1$ integrin, or $\mathbf{C}$. blocking antibody against $\beta 1$ integrin $(10 \mu \mathrm{g} / \mathrm{ml})$. After 5 days of culture, cell density was evaluated by phase contrast microscopy. Values represent the mean \pm S.E.M. of three independent experiments (N.S. = not significant). 
order to exclude the role of RAGE in the increase of cell proliferation in old collagen, cell proliferation was analyzed in HT-1080 cells stably transfected with empty vector (HT-1080 Neo), human full length RAGE (HT-1080 Full RAGE) and dominant negative RAGE (HT-1080 DN RAGE) [20]. As shown in Figure 3B and 3C, cell proliferation of HT-1080 Neo and HT-1080 DN RAGE cells increased in old collagen when compared to the adult one. This increase was similar to that observed in parental HT-1080 cells. Expression of full RAGE in HT-1080 cells (HT-1080 Full RAGE) did not induce any significant increase in cell proliferation in old collagen when compared to the other cell lines. Altogether, these data indicate that RAGE is not involved in the increase of cell proliferation in old collagen.

\section{A}

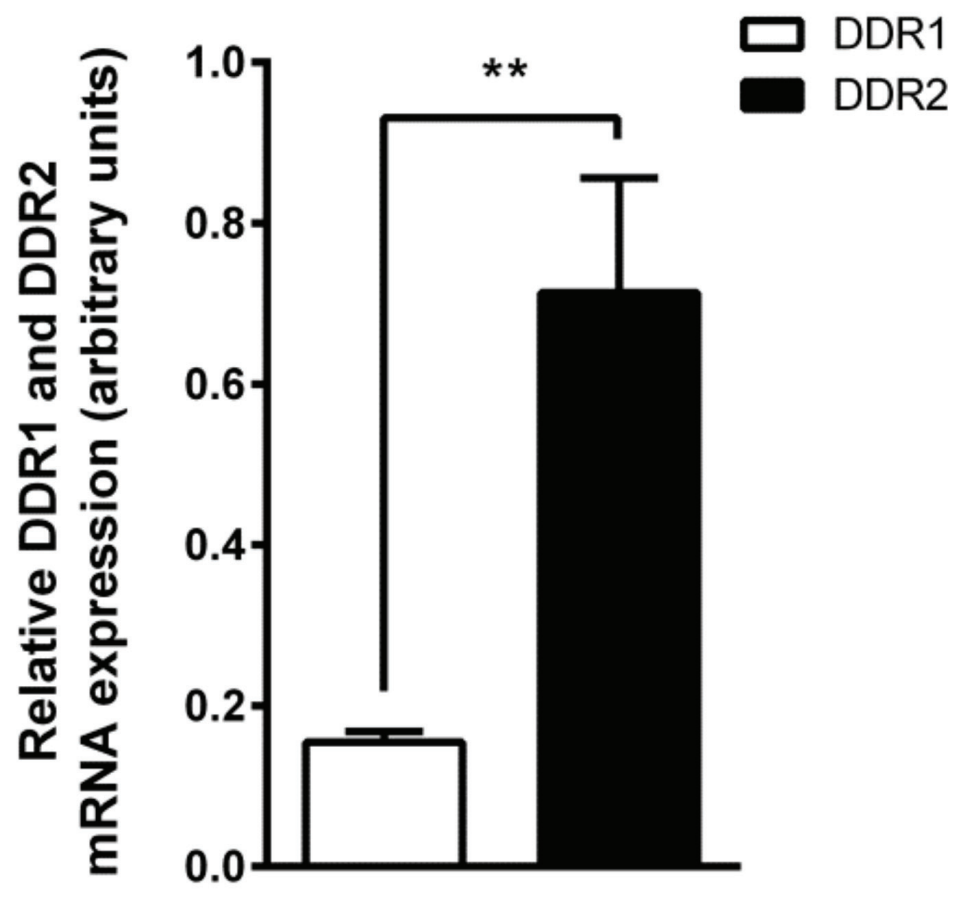

B
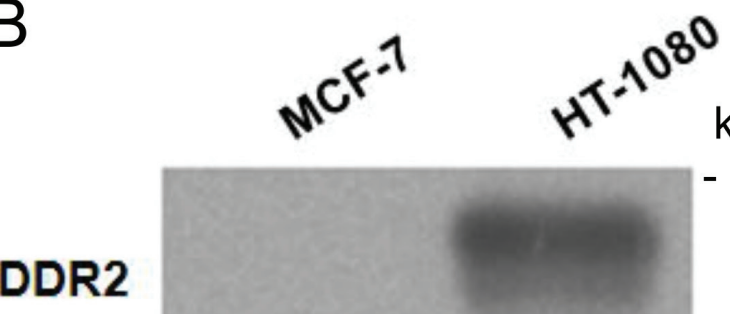

$\mathrm{kDa}$

$-140$
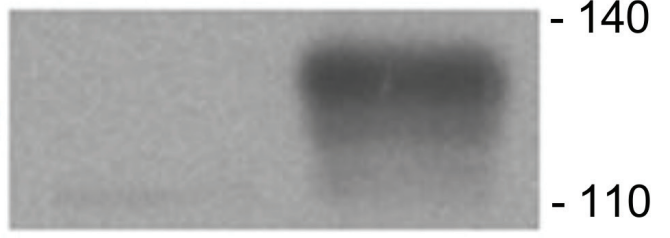

DDR1

$-110$
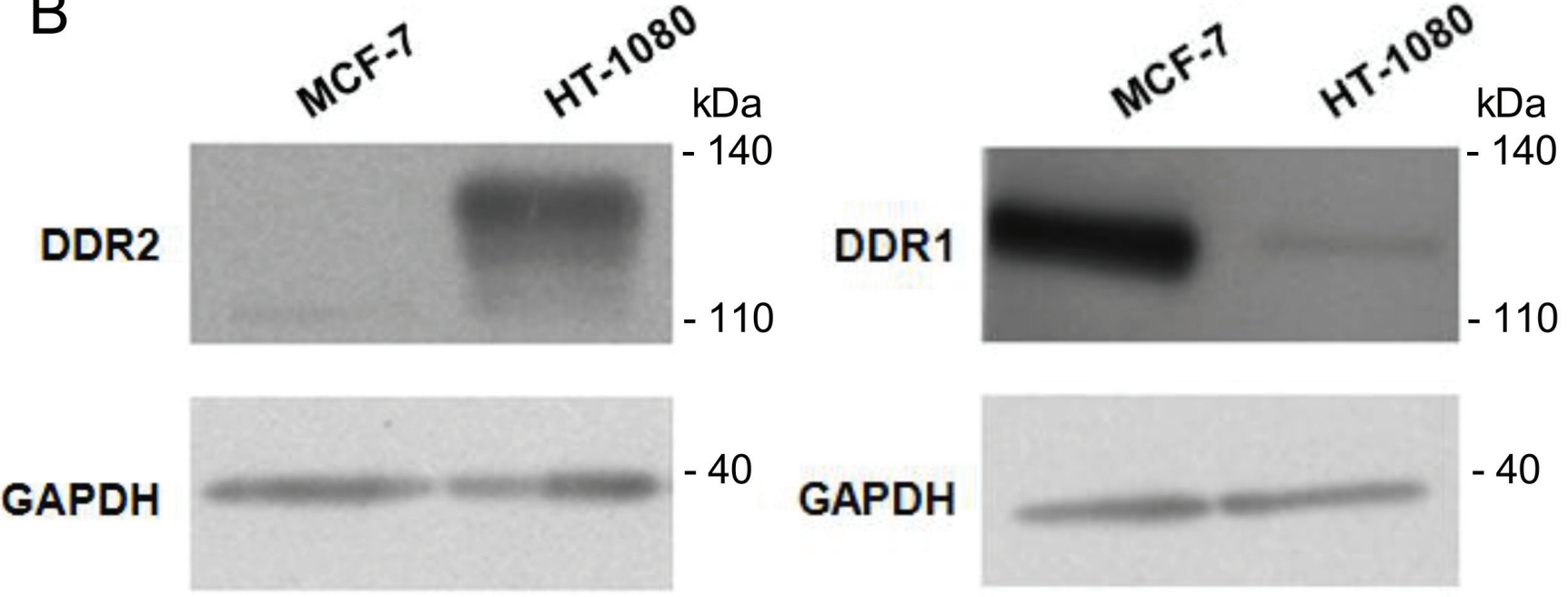

Figure 5: DDR1 and DDR2 expression in HT-1080 and MCF-7 cells. HT-1080 and MCF-7 cells were cultured on plastic. A. DDR2 and DDR1 transcripts contents in HT-1080 cells were evaluated by real-time quantitative polymerase chain reaction. B. DDR2 (left panel) and DDR1 (right panel) protein expression was analyzed by western blot. Glyceraldehyde 3-phosphate dehydrogenase (GAPDH) was used as a loading control. Data shown are representative of three independent experiments $(* * p<0.01, * * * p<0.001)$. 
DDR2 but not $\beta 1$ integrin is involved in the regulation of HT-1080 cell proliferation

A number of different transmembrane collagen receptors have been identified, with the integrin family being the best studied [21]. The primary collagen binding integrins are the $\alpha 1 \beta 1$ and $\alpha 2 \beta 1$ heterodimers [22]. Since we had previously demonstrated by flow cytometry that HT-1080 cells express $\beta 1$ integrin [23], we investigated whether this integrin mediates the regulation of HT-1080 cell proliferation. siRNA was used to deplete $\beta 1$ integrin in HT-1080 (Figure 4A), and cell proliferation was assessed in adult and old collagen. Figure 4B shows that $\beta 1$ integrin depletion did not affect HT-1080 cell proliferation in both collagens, when compared to cells treated with control siRNA. Since cell proliferation was evaluated after 5 days culture, we analyzed $\beta 1$ integrin mRNA expression using q-PCR after 2 and 5 days culture in 3D matrices. As shown in the supplementary data $2 \mathrm{~A}, \beta 1$ integrin mRNA expression substantially decreased after 2 days culture. This expression was moderately decreased after 5 days culture. Preventing the involvement of integrin and collagen by using a blocking antibody against $\beta 1$ integrin did not however modify cell proliferation in adult and old collagens (Figure 4C). Altogether, these data indicate that $\beta 1$ integrin is not involved in the increase of HT-1080 cell proliferation in aged collagen.
DDR1 and DDR2 are collagen-binding receptors belonging to the receptor tyrosine kinase (RTK) family. To determine whether these receptors play a role in the regulation of HT-1080 cell proliferation, we first evaluated DDR1 and DDR2 expression in these cells. Quantitative PCR analysis shows in Figure 5A that DDR2 mRNA was preferentially expressed in HT-1080 cells. These data were confirmed by Western blot, showing that DDR2 was significantly more expressed than DDR1 in HT-1080 cells (Figure 5B). MCF-7 cells were used here as a negative control for DDR2 [24] and a positive control for DDR1 [25].

The involvement of DDR2 in HT-1080 cell proliferation was then investigated. To this end, DDR2 siRNA was used to knockdown DDR2 (Figure 6A). Figure $6 \mathrm{~B}$ shows that DDR2 depletion promotes cell proliferation in adult collagen but not in the old one. As previously performed for $\beta 1$ integrin siRNA (supplementary data $2 \mathrm{~A}$ ), we analyzed also DDR2 mRNA expression using q-PCR after 2 and 5 days culture in 3D matrices. As shown in the supplementary data 2B, DDR2 mRNA expression highly decreased after 2 days culture. However, this expression increased to the same level observed in control cells after 5 days culture. These data were confirmed by using nilotinib, a well-known inhibitor of DDR2 kinase activity [26]. Nilotinib at non-toxic concentration (100 nM) was able to restore cell proliferation in adult collagen to a level
A

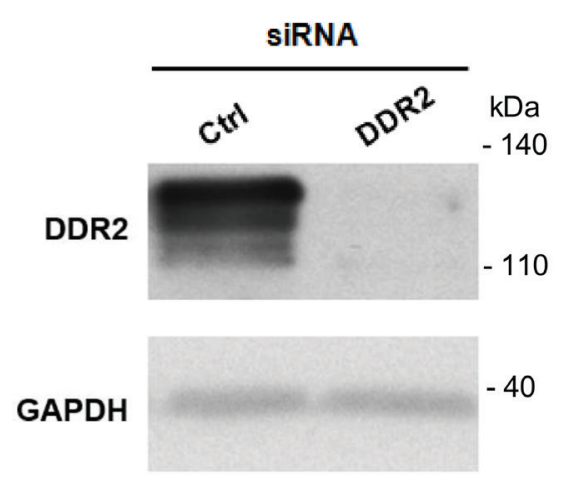

B

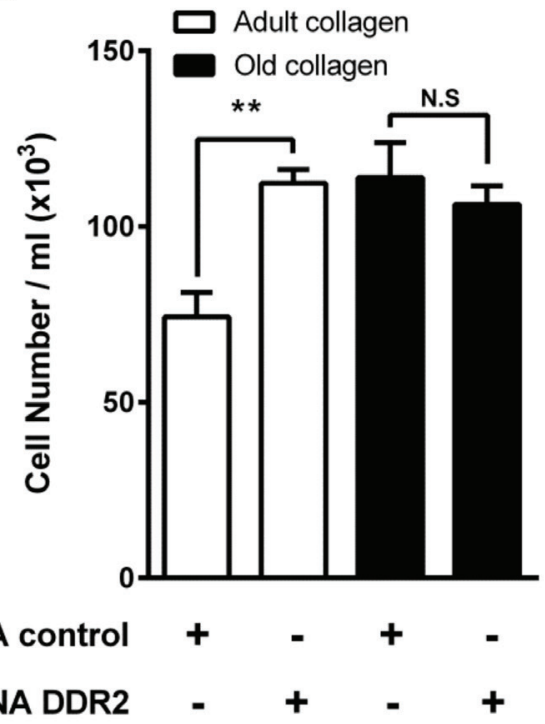

C

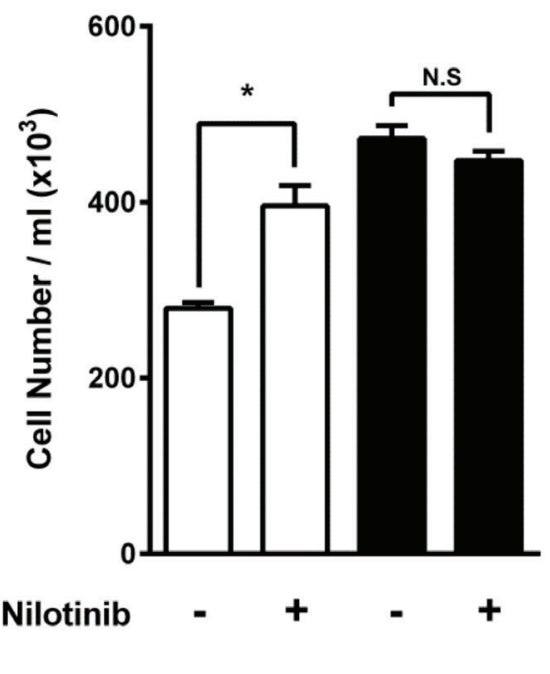

Figure 6: Effect of DDR2 inhibition on HT-1080 cell proliferation. A. HT-1080 cells were transfected with control siRNA (Ctrl) or DDR2 siRNA. DDR2 expression was analyzed by immunoblotting. GAPDH was used as a loading control. B. HT-1080 cells were seeded in adult and old type I collagen 3D matrices at a density of $1.5 \times 10^{4} \mathrm{cells} / \mathrm{ml}$, with or without siRNA directed against DDR2. After 5 days of culture, cell density was evaluated by phase contrast microscopy. C. HT-1080 cells were seeded in adult and old type I collagen $3 \mathrm{D}$ matrices at a density of $5 \times 10^{4}$ cells $/ \mathrm{ml}$, with or without DDR2 inhibitor nilotinib at $100 \mathrm{nM}$. After 5 days of culture, cell density was evaluated by phase contrast microscopy. Values represent the mean \pm S.E.M. of three independent experiments $\left({ }^{*} p<0.05, * * p<0.01\right.$, N.S. $=$ not significant). 
similar to that observed in the old one (Figure 6C). As nilotinib may inhibit other kinases in addition to DDR2, we investigated whether nilotinib was able to restore cell proliferation in HT-1080 cells expressing the gatekeeper DDR2 form (T654I), which is not sensitive to nilotinib $[27,28]$. As shown in the supplementary data 3A, HT1080 cells expressed the same level of DDR2 protein when transfected with wild-type and gatekeeper form of DDR2. In the presence of nilotinib, the proliferation did not increase in cells expressing gatekeeper DDR2 form when compared to those expressing the wild-type form of the receptor (supplementary data 3A). These data suggest that DDR2 regulates differentially HT-1080 cell proliferation in adult and old 3D collagen matrices.

\section{DDR2 is highly activated in adult collagen}

Several reports suggest that DDR2 is a tyrosine kinase receptor with the unique ability to be activated by fibrillar collagen [11]. Contrary to other classical growth factor-activated RTKs which display rapid and transient activation, DDR2 exhibit delayed and sustained phosphorylation upon binding to collagen. Its expression in HT-1080 cells in adult and old collagen was first analyzed. Figure 7A shows that DDR2 expression levels were similar in both collagens. In order to investigate whether DDR2 was differentially activated in adult and old collagen, HT-1080 cells were seeded in collagen 3D matrices. DDR2 was immunoprecipitated from cell lysates and its phosphorylated form was detected by immunoblotting. As shown in Figure 7B, DDR2

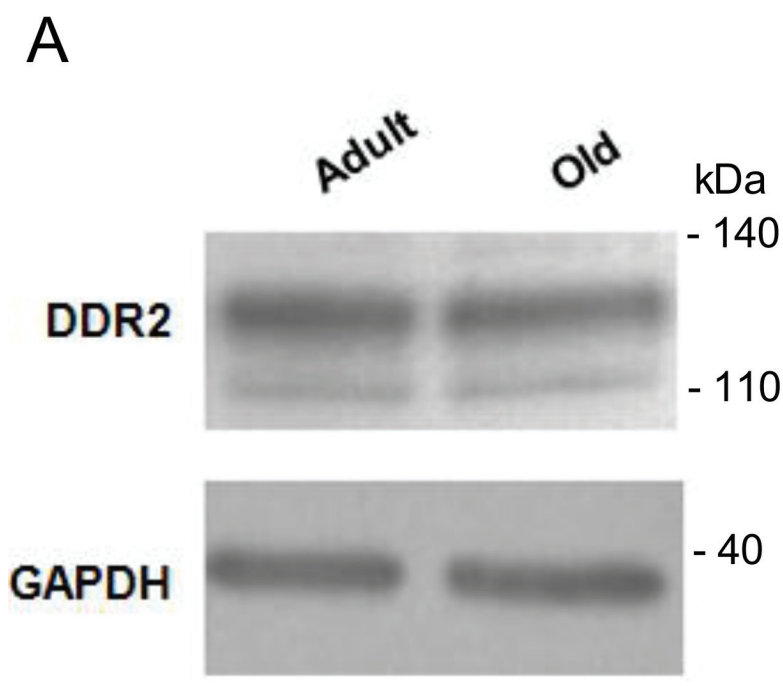

B

\section{IP : Anti DDR2}
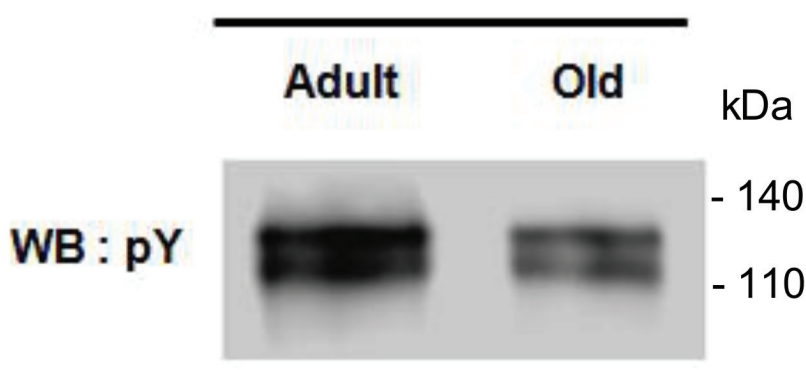

WB : DDR2

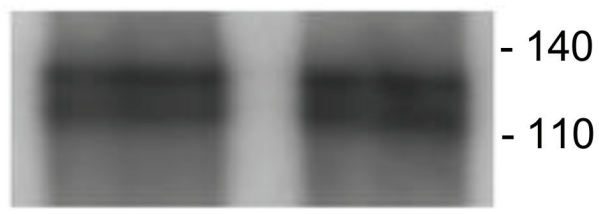

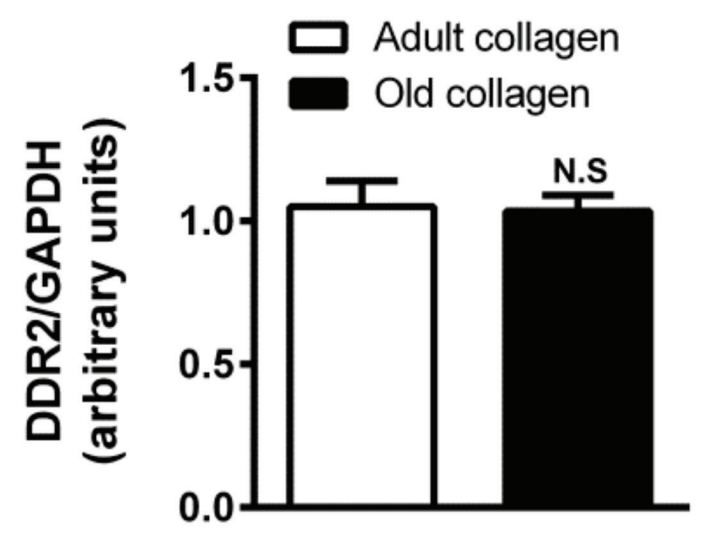

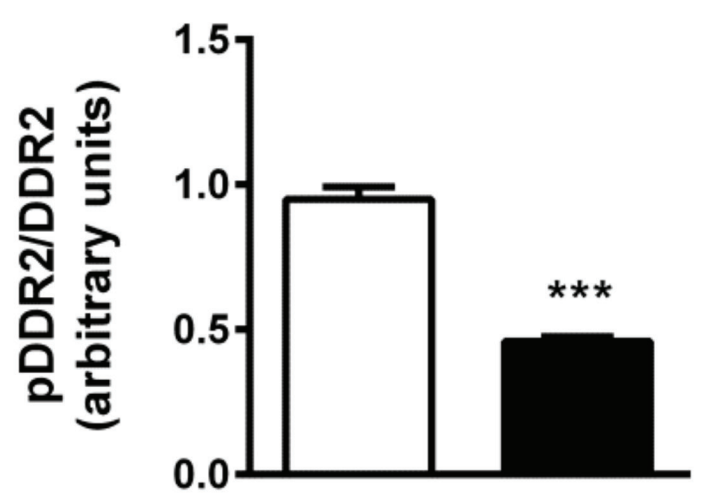

Figure 7: Effect of collagen aging on DDR2 expression and activation. HT-1080 cells were serum starved during 12 hours, then cultured 6 hours in adult and old type I collagen 3D matrices. A. Western blot analysis was performed using anti-DDR2 specific antibody. The histogram shows the ratio of DDR2 expression relative to the loading control GAPDH. B. Immunoprecipitation was performed using anti-DDR2 specific antibody, and DDR2 activation was measured by western blot using anti-phosphotyrosine specific antibody. The histogram shows the ratio of pDDR2 expression relative to DDR2. Values represent the mean \pm S.E.M. of three independent experiments $(* * * p<0.001$, N.S. $=$ not significant $)$. 
phosphorylation was 2-fold higher in adult collagen when compared to the old one $(p<0.001)$. As for cell proliferation, we then analyzed the activation of DDR2 in A204 sarcoma cells in collagen 3D matrices. As shown in the supplementary data 1B, DDR2 phosphorylation was also higher in adult collagen when compared to the old one. Since the cell proliferation rate was similar on adult and old 2D collagen coating, we investigated whether DDR2 activation was similar or not in these conditions. As shown in the supplementary data 4, DDR2 phosphorylation in the case of adult $2 \mathrm{D}$ collagen coating was similar to that observed in the case of the older one.

A

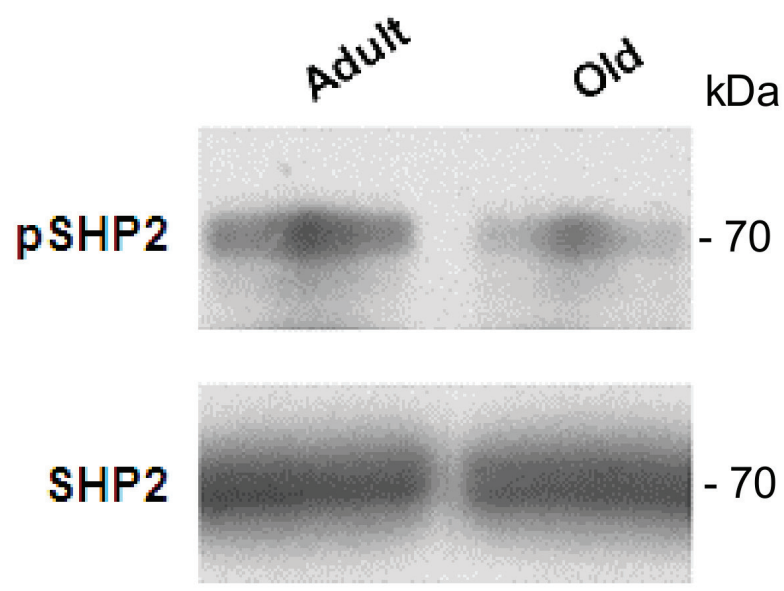

$\mathrm{kDa}$

70

70

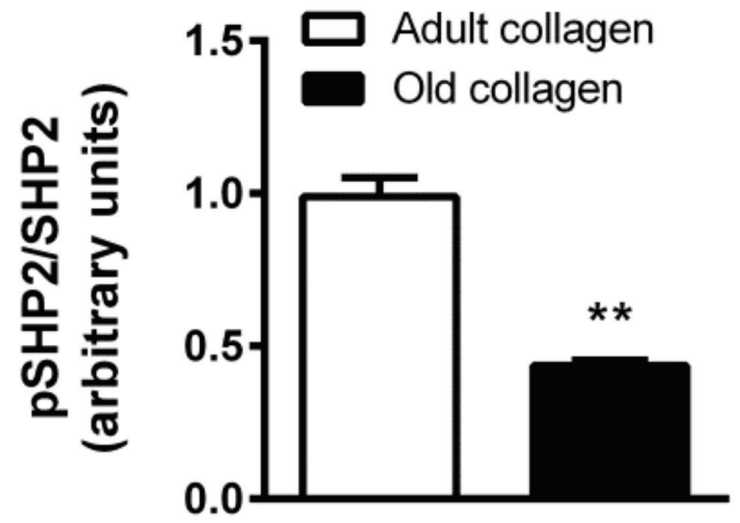

This suggests that the $3 \mathrm{D}$ matrix model is crucial for the differential DDR2 activation with type I collagen aging.

The primary DDR2 downstream target SHP-2 is highly activated in adult collagen

DDR2 has been shown to phosphorylate the tyrosine phosphatase SHP-2 when activated with fibrillar type I collagen [29]. To elucidate whether SHP2 is also involved as a downstream effector of DDR2 in our model, HT-1080 cells were seeded in adult and old
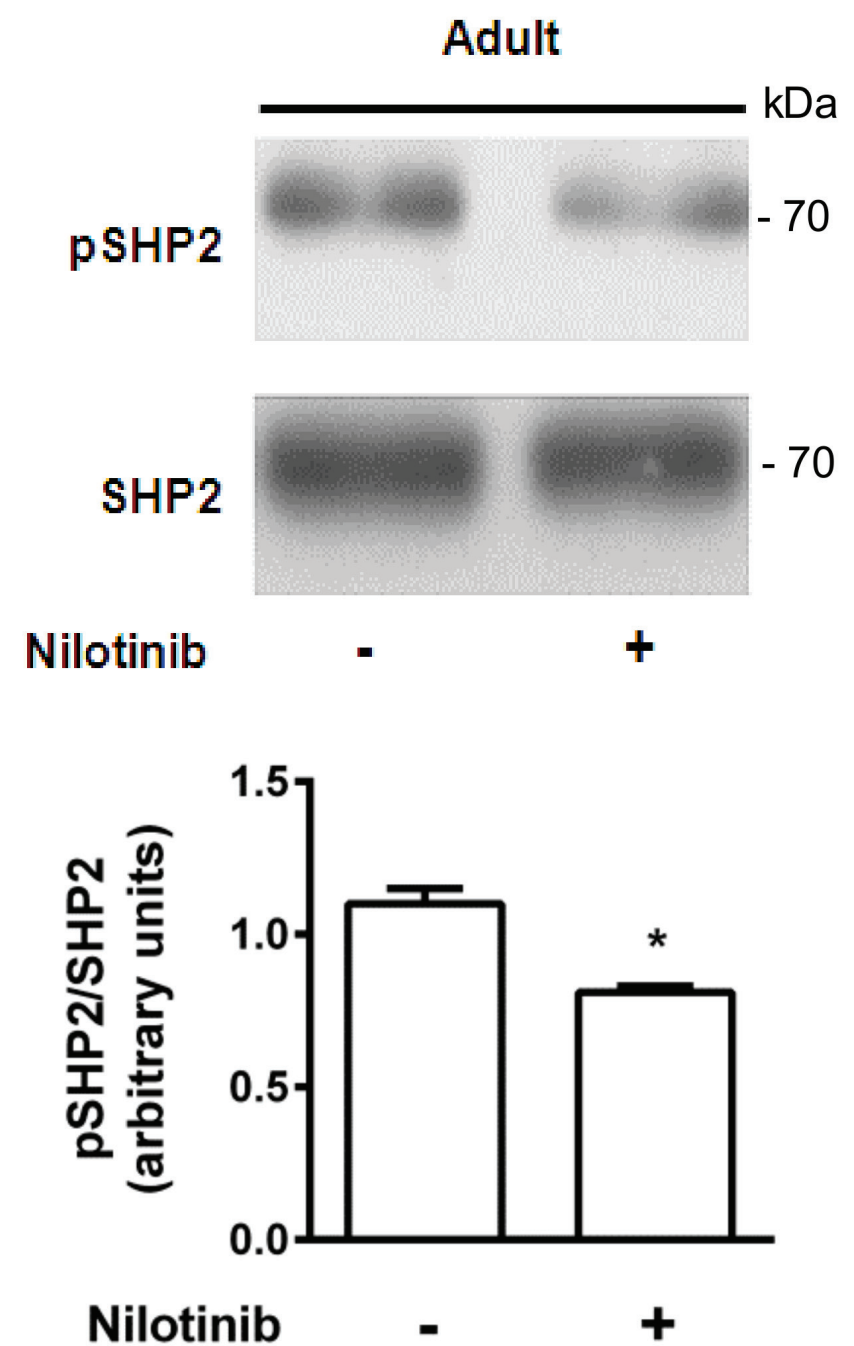

Figure 8: Effect of collagen aging on SHP-2 activation. A. HT-1080 cells were serum starved during 12 hours, then cultured 6 hours in adult and old type I collagen 3D matrices. Western blot analysis was performed using anti-pSHP-2 and SHP-2 specific antibodies. The histogram shows the ratio of pSHP-2 expression relative to SHP-2. B. HT-1080 cells were serum starved during 12 hours, then cultured 6 hours in adult type I collagen 3D matrices, with or without $100 \mathrm{nM}$ of nilotinib. Western blot analysis was performed using anti-pSHP-2 and SHP-2 specific antibodies. The histogram shows the ratio of pSHP-2 expression relative to total SHP-2. Values represent the mean \pm S.E.M. of three independent experiments $\left({ }^{*} p<0.05,{ }^{*} p<0.01\right)$. 
A

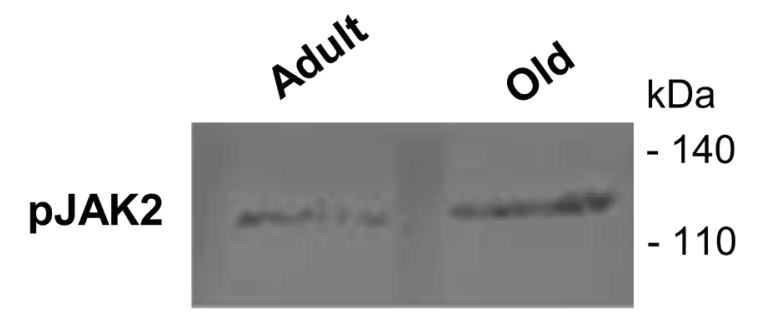

JAK2

$-140$

$-110$

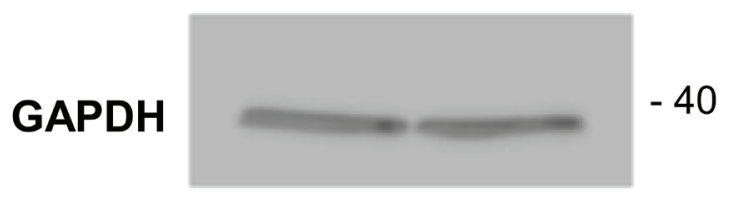

B

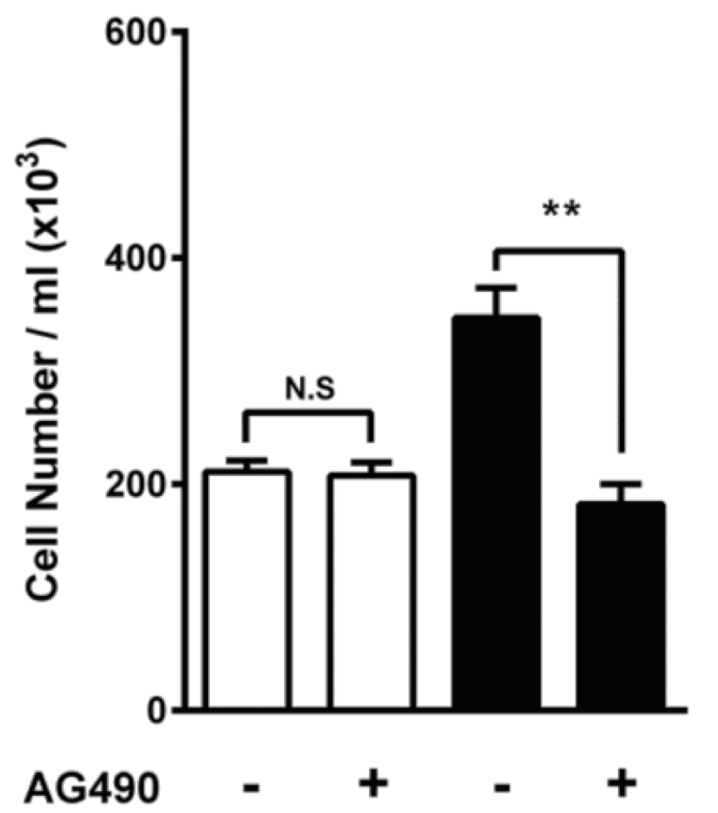

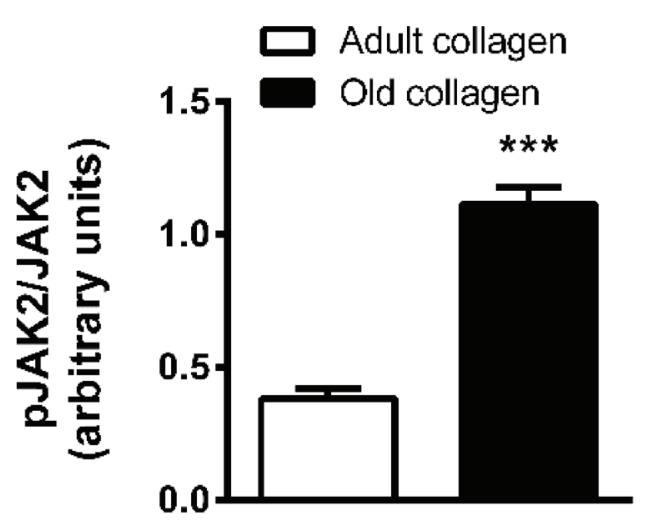

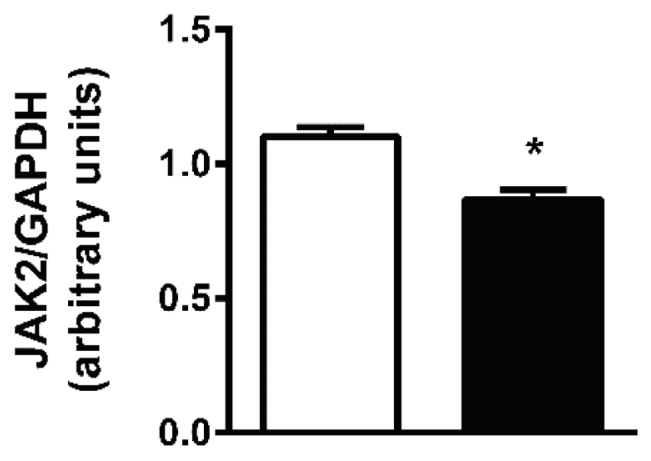

C

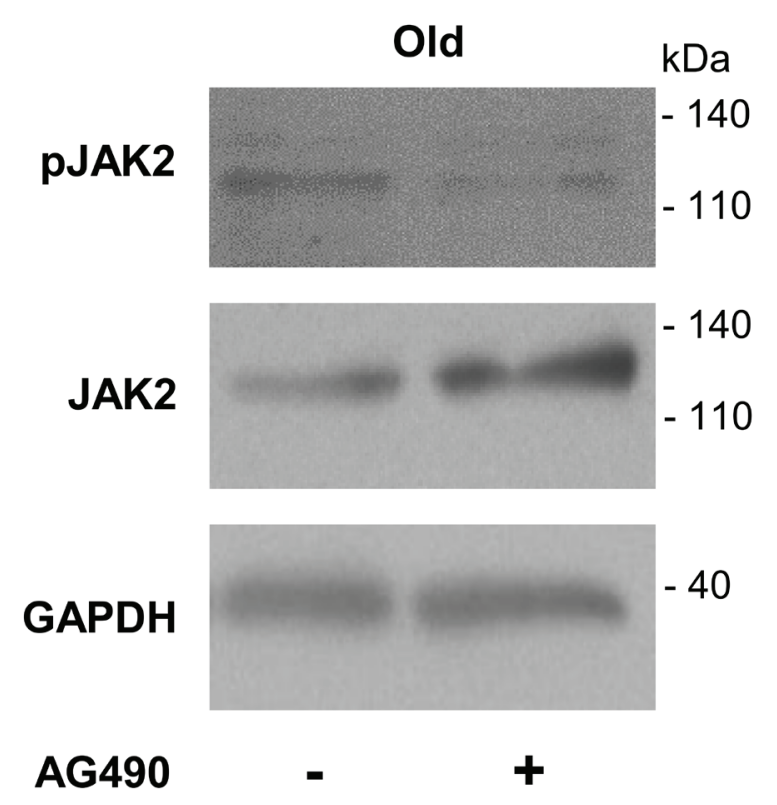

Figure 9: Effect of collagen aging on JAK2 activation and HT-1080 cell proliferation. HT-1080 cells were cultured 5 days in adult and old type I collagen 3D matrices. A. Western blot analysis was performed using pJAK2 and JAK2 specific antibodies. The histogram shows the ratio of pJAK2 and JAK2 expression relative to JAK2 and GAPDH respectively. B. HT-1080 cells were seeded in adult and old type I collagen 3D matrices at a concentration of $1.5 \times 10^{4} \mathrm{cells} / \mathrm{ml}$, with or without $10 \mu \mathrm{M}$ of the JAK2 inhibitor AG490. After 5 days of culture, cell density was evaluated by phase contrast microscopy and $\mathbf{C}$. western blot analysis was performed using pJAK2 and JAK2 specific antibodies. Values represent the mean \pm S.E.M. of three independent experiments $\left({ }^{*} p<0.05,{ }^{* *} p<0.01,{ }^{* * *} p<0.001\right)$. 
collagen matrices for 6 hours. Then, Western blotting experiments were performed in order to analyze SHP-2 expression and Tyr-542 phosphorylation. Figure 8A shows that SHP-2 expression was similar for both collagens, whereas SHP-2 phosphorylation was increased 2-fold in adult collagen compared to the old one. As shown in the supplementary data $1 \mathrm{C}$, SHP-2 phosphorylation also increased in A204 cells in adult collagen. When DDR2 expression was suppressed in HT-1080 cells using siRNA, SHP-2 phosphorylation decreased in adult collagen (supplementary data 5A). In adult collagen, SHP-2 phosphorylation was inhibited by approximatively $30 \%$ when HT-1080 cells were treated with $100 \mathrm{nM}$ nilotinib (Figure 8B). In order to show that nilotinib induced this effect by inhibiting specifically DDR2, we investigated whether SHP-2 phosphorylation was inhibited by nilotinib in gatekeeper DDR2 expressing cells. As shown in the supplementary data 3B, SHP-2 phosphorylation level was similar when cells were treated or not with nilotinib. Taking into account that nilotinib was able to increase cell proliferation in adult collagen (Figure 6), these data suggest that DDR2 downregulates cell proliferation in adult collagen by SHP-2 downstream activation.

\section{JAK2 phosphorylation is downregulated in adult collagen}

The Tyr-1007 site of JAK2 has been reported to be dephosphorylated by tyrosine phosphatase SHP-2 [30]. In order to determine whether SHP-2 activation in the presence of adult collagen is able to downregulate JAK2 phosphorylation, JAK2 expression and phosphorylation were analyzed by Western blott. Figure 9A shows that JAK2 phosphorylation level was 3-fold lower in adult collagen than in the old one. As shown in supplementary data $1 \mathrm{C}$, JAK2 phosphorylation was also decreased in A204 cells in adult collagen. It is important to note that in both cell lines, JAK2 expression was significantly decreased in the presence of old collagen. In order to investigate whether kinase function of DDR2 was involved in the activation of JAK2, we analyzed JAK2 phosphorylation in wild-type and gatekeeper DDR2 expressing cells in the presence or not of $100 \mathrm{nM}$ nilotinib. As shown in supplementary data $3 \mathrm{~B}$, nilotinib was able to increase JAK2 phosphorylation in wildtype DDR2 expressing cells but not in gatekeeper ones. When SHP-2 expression was suppressed in HT-1080 cells using siRNA, JAK2 phosphorylation increased in adult collagen (supplementary data 6). To establish whether JAK2 phosphorylation was involved in the increase of cell proliferation in old collagen, we analyzed cell proliferation in the presence of the p-JAK2 inhibitor AG490 in both collagens. At $10 \mu \mathrm{M}$ concentration, AG490 was able to decrease HT-1080 cell proliferation in old collagen but not in the adult one (Figure 9B). To demonstrate that the inhibition of cell proliferation in the presence of AG490 was due to a decrease in JAK2 activation, JAK2 phosphorylation was analyzed after AG490 treatment. As shown in Figure 9C, AG490 induced a decrease in JAK2 phosphorylation.

\section{ERK1/2 phosphorylation is downregulated by adult collagen}

ERK1/2 pathway has been shown to be phosphorylated by p-JAK2 [31] and is known to promote cell proliferation in various cell models [32]. To determine whether ERK1/2 was differentially activated in adult and old collagen, ERK1/2 phosphorylation was analyzed by Western blot. Figure $10 \mathrm{~A}$ indicates that ERK1/2 phosphorylation was 2-fold lower in adult collagen when compared to the old one $(p<0.05)$. As shown in the supplementary data $1 \mathrm{D}$, ERK1/2 phosphorylation was also decreased in A204 cells in adult collagen. In order to verify whether ERK1/2 function upregulates cell proliferation in old collagen, cells were treated with the ERK1/2 phosphorylation inhibitor U0126. Figure 10B shows that U0126 was able to decrease cell proliferation in old collagen to a level close to that of the adult one. In order to verify if there is a relationship between JAK2 activity and ERK1/2 phosphorylation in old collagen, cells were treated with the JAK2 inhibitor AG490 before analysis of ERK1/2 phosphorylation. As shown in Figure 11A, ERK1/2 phosphorylation was 2-fold lower when cells were treated with AG490 in old collagen. To establish a link between DDR2 activation and ERK1/2 pathway inhibition, DDR2 expression was suppressed in HT-1080 cells using siRNA and ERK1/2 pathway was analyzed in adult collagen. ERK1/2 phosphorylation was increased (supplementary data 5B). ERK1/2 activation was also analyzed after nilotinib treatment in adult collagen. As shown in Figure 11B, ERK1/2 phosphorylation was increased 3-fold in the presence of nilotinib compared to control cells. In order to show that nilotinib induced this effect by inhibiting specifically DDR2, we investigated whether ERK1/2 phosphorylation was increased by nilotinib in gatekeeper DDR2 expressing cells. As shown in the supplementary data $3 \mathrm{C}$, ERK1/2 phosphorylation level was similar when cells were treated or not with nilotinib.

\section{p21 ${ }^{\text {CIP1 }}$ expression is upregulated in adult collagen}

The cyclin inhibitor $\mathrm{p} 21^{\mathrm{CIP} 1}$ is well known to downregulate cell cycle progression and to inhibit cell proliferation. As shown in Figure $10 \mathrm{C}, \mathrm{p} 21^{\mathrm{CIP} 1}$ expression was 3-fold higher in adult collagen relative to the old one. As shown in the supplementary data $1 \mathrm{D}, \mathrm{p} 21^{\mathrm{CIP}}$ expression also increased in A204 cells in adult collagen. In order to determine whether this negative regulatory control of 
A
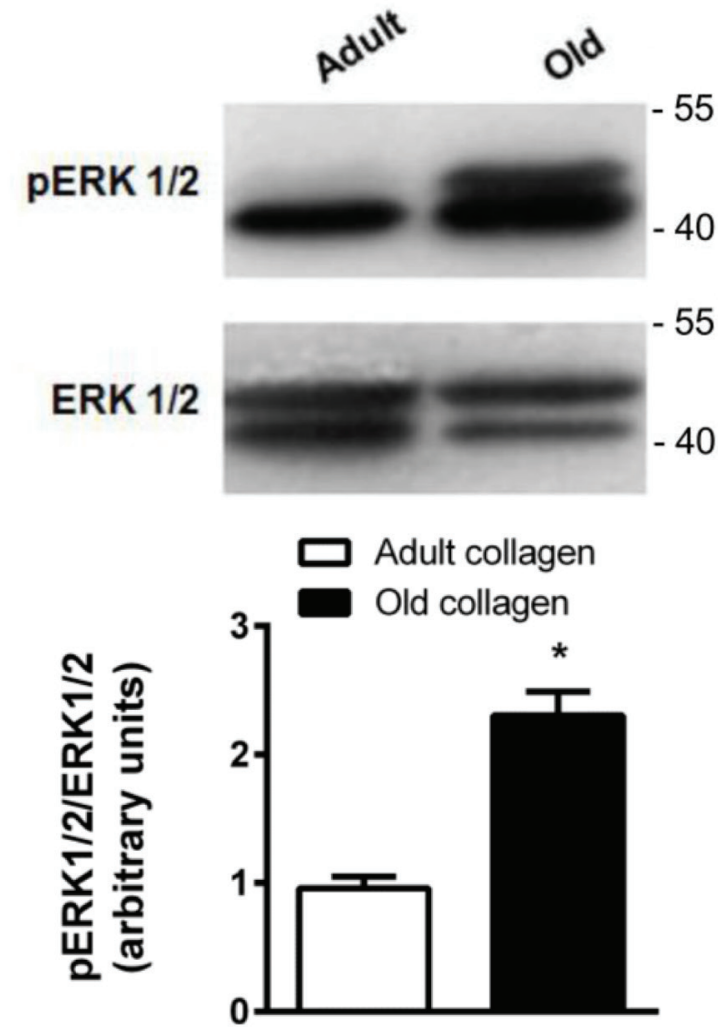

B

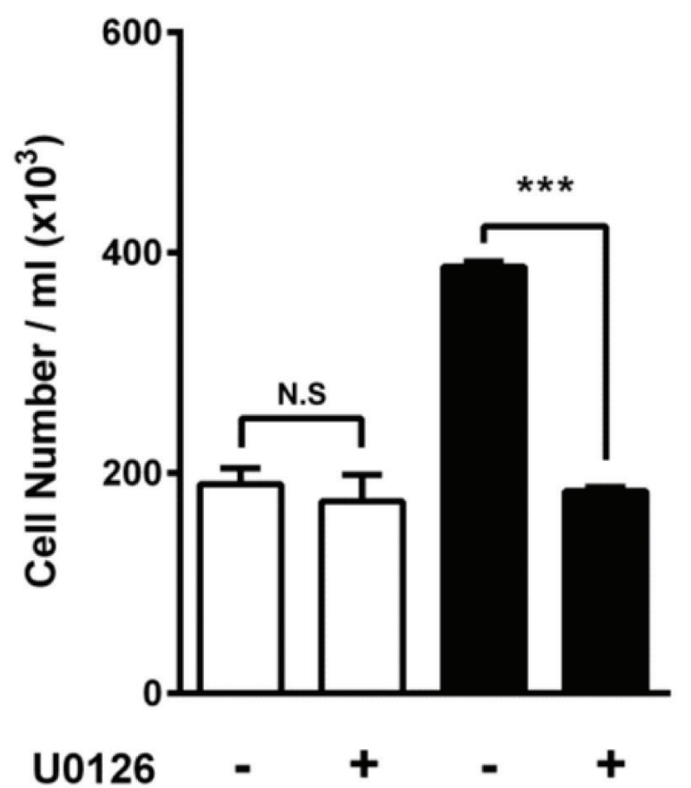

C

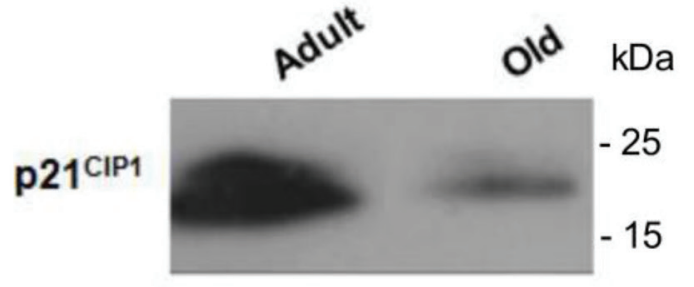

GAPDH
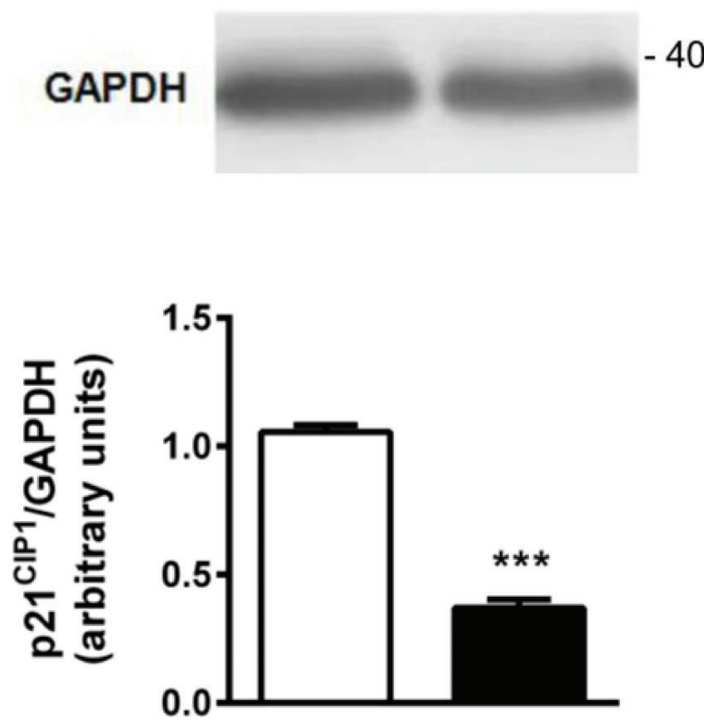

Figure 10: Effect of collagen aging on ERK1/2 activation and p21 ${ }^{\text {CIP1 }}$ expression. A. ERK1/2 western blot analysis of HT1080 cells after 5 days culture in adult and old type I collagen 3D matrices. The histograms show the ratio of pERK $1 / 2$ expression relative to total ERK1/2. B. Effect of ERK1/2 inhibitor U0126 on cell proliferation. HT-1080 cells were seeded in adult and old type I collagen 3D matrices at a density of $1.5 \times 10^{4}$ cells $/ \mathrm{ml}$, with or without $5 \mu \mathrm{M}$ U0126. After 5 days of culture, cell density was evaluated by phase contrast microscopy. C. p2 $1^{\mathrm{CIP1}}$ western blot analysis of HT-1080 cells after 5 days culture in adult and old type I collagen 3D matrices. The histograms show the ratio of $\mathrm{p} 21^{\mathrm{CIP1}}$ expression relative to GAPDH. D. Effect of U0126 on pERK1/2 and p $21^{\mathrm{CIP1}}$ expression. HT-1080 cells were seeded in adult and old type I collagen 3D matrices at a density of $1.5 \times 10^{4} \mathrm{cells} / \mathrm{ml}$, with or without $5 \mu \mathrm{M} \mathrm{U} 0126$. After 5 days of culture, western blot analysis was performed using $\mathrm{pERK} 1 / 2$ and $\mathrm{p} 21^{\mathrm{CIP1}}$ specific antibodies. Values represent the mean \pm S.E.M. of three independent experiments $\left({ }^{*} p<0.05,{ }^{* * *} p<0.001\right)$. 

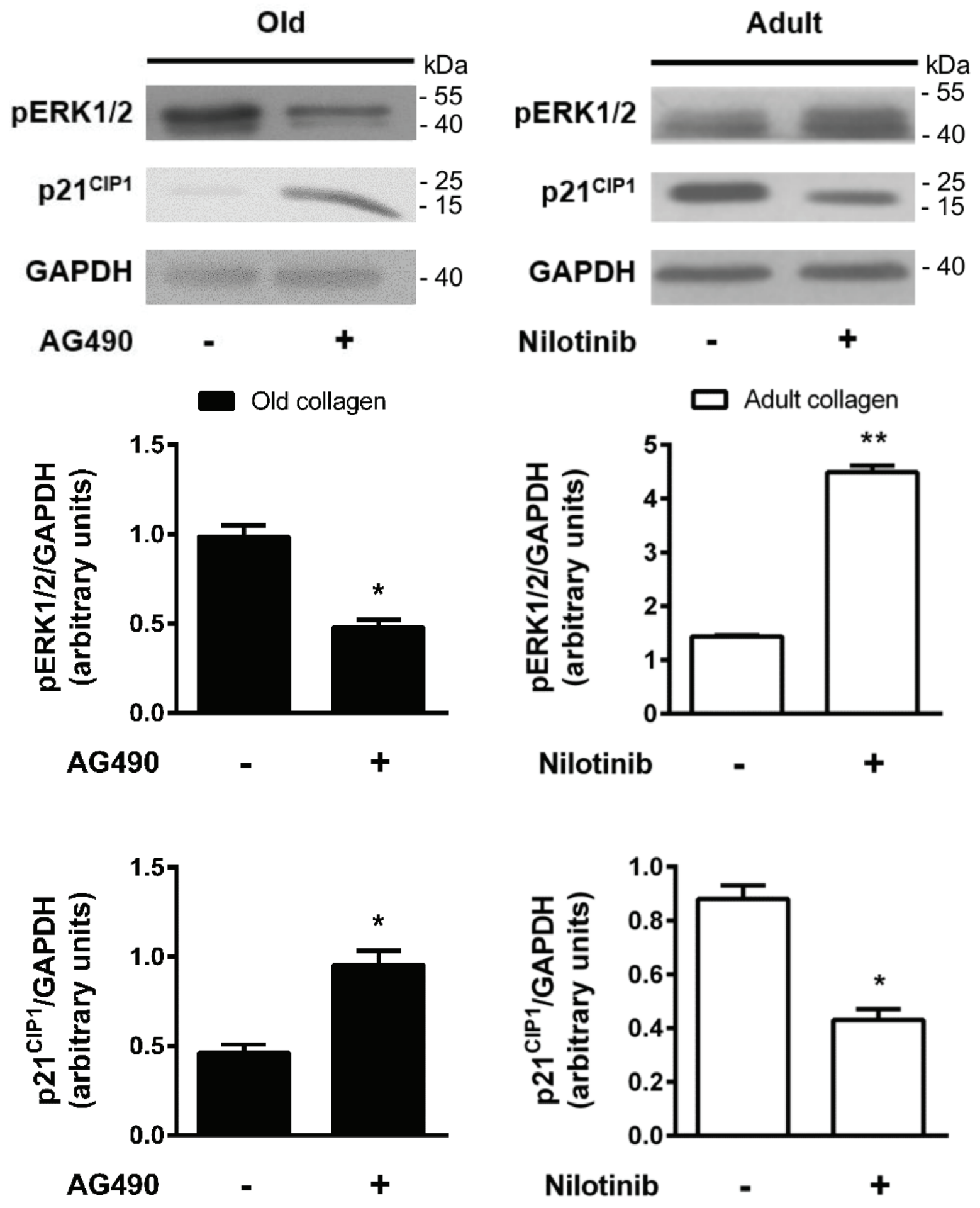

Figure 11: Effect of DDR2 and JAK2 inhibition on ERK1/2 activation and p21 ${ }^{\text {CIP1 }}$ expression. A. HT-1080 cells were cultured 5 days in old type I collagen 3D matrices, with or without $10 \mu \mathrm{M}$ of AG490. Western blot analysis was performed using pERK1/2 and $\mathrm{p} 21^{\mathrm{CIP} 1}$ specific antibodies. The histograms show the ratio of pERK1/2 and $\mathrm{p} 21^{\mathrm{CIP} 1}$ expression relative to GAPDH. B. HT-1080 cells were culture 5 days in adult type I collagen 3D matrices, with or without $100 \mathrm{nM}$ of nilotinib. Western blot analysis was performed using pERK1/2 and $\mathrm{p} 21^{\mathrm{CIP} 1}$ specific antibodies. The histograms show the ratio of pERK1/2 and $\mathrm{p} 21^{\mathrm{CIP} 1}$ expression relative to GAPDH. Values represent the mean \pm S.E.M. of three independent experiments $\left(* p<0.05,{ }^{* *} p<0.01\right)$. 
p $21^{\mathrm{CIP} 1}$ expression involved ERK1/2 phosphorylation [33], cells were treated with the ERK1/2 phosphorylation inhibitor U0126. Figure 10D shows that U0126 was able to increase $\mathrm{p} 21^{\mathrm{CIP} 1}$ expression in old collagen. In order to verify if there is a relationship between JAK2 activity and $\mathrm{p} 21^{\mathrm{CIP} 1}$ expression in old collagen, cells were treated with the JAK2 inhibitor AG490 before analysis of p $21^{\mathrm{CIP} 1}$ expression. As shown in Figure 11A, p $21^{\mathrm{CIP} 1}$ expression was 2-fold higher when cells were treated with AG490 in old collagen. Finally, to establish a link between DDR2 activation and p2 $1^{\mathrm{CIP} 1}$ expression, DDR2 expression was suppressed in HT-1080 cells using siRNA and $\mathrm{p} 21^{\mathrm{CIP} 1}$ expression was analyzed in adult collagen. As shown in the supplementary data $5 \mathrm{~B}, \mathrm{p} 21^{\mathrm{CIP} 1}$ expression was decreased. p21 $1^{\mathrm{CIP} 1}$ expression was also analyzed after nilotinib treatment in adult collagen. As shown in Figure 11B, nilotinib induced a 2-fold decrease in p21 $1^{\mathrm{CIP} 1}$ expression. As for ERK1/2, and in order to show that nilotinib induced this effect by inhibiting specifically DDR2, we investigated whether $\mathrm{p} 21^{\mathrm{CIP} 1}$ expression was decreased by nilotinib in gatekeeper DDR2 expressing cells. As shown in the supplementary data $3 \mathrm{C}, \mathrm{p} 21^{\mathrm{CIP} 1}$ expression level was similar when cells were treated or not with nilotinib.

\section{DISCUSSION}

The ECM, which was previously considered as a physical scaffold playing a role in tissue organization, is currently recognized as a key regulator of signaling pathways involved in cell and tissue functions. Several works have been reported on the dynamic interplay between type I collagen, the major component of ECM in interstitial tissue, and tumor [34]. To understand this cross-talk, previous published works have already shown that type I collagen is able to restrict proliferation of cancer cells [35-37]. Proliferative responses seemed to be related to $3 \mathrm{D}$ culture conditions $[38,39]$. Thus, such 3D in vitro models provide a bridge between $2 \mathrm{D}$ cell culture and in vivo models. Several groups using $3 \mathrm{D}$ models

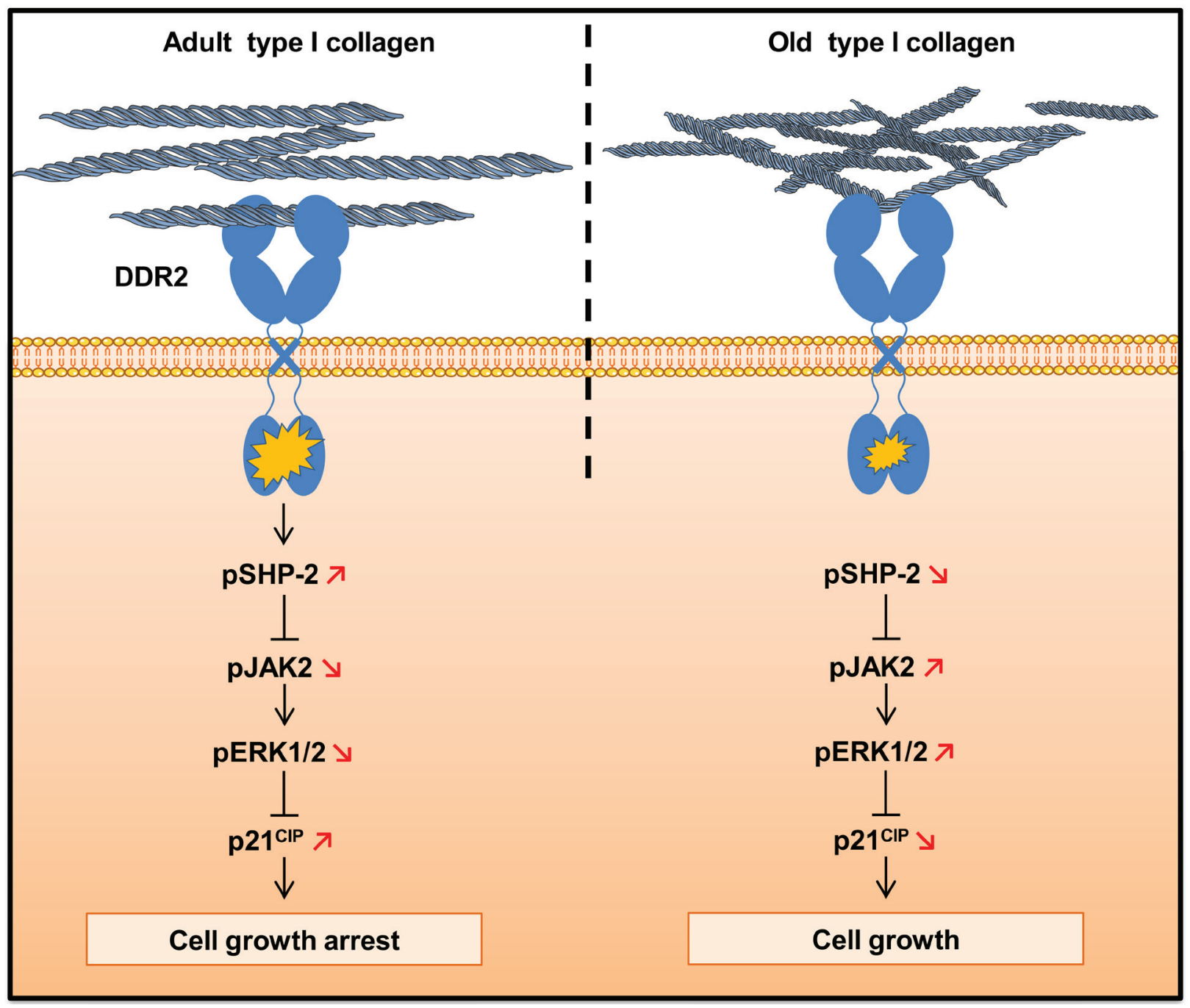

Figure 12: Schematic drawing of DDR2-induced cell growth regulation by type I collagen aging. 
demonstrated that tumor cell proliferation was restricted in the presence of type I collagen $[7,37,40]$.

In this work, we aimed at analyzing the effect of collagen aging on HT-1080 tumor cell proliferation. We report evidence that proliferation of HT-1080 cells is higher in old collagen when compared to the adult one. This is in agreement with previously reported data on lung [5], and prostate [41] carcinomas. The culture model was crucial since the observed difference in cell proliferation occurred in 3D but not in 2D cell culture systems. Using siRNA strategy and blocking antibodies, we show that this regulation does not involve $\beta 1$ integrin in $3 \mathrm{D}$ conditions. In addition, in our recent findings collagen $3 \mathrm{D}$ conditions induce a rapid and marked decrease in $\beta 1$ integrin expression in HT-1080 cells [23]. This support the fact that $\beta 1$ integrin is not involved in the differential regulation of cell proliferation. Using blocking antibodies and antagonists against RAGE, we also demonstrate that the AGE/RAGE axis is not involved. Consistently, HT1080 cell treatment with glycated bovine serum albumin did not increase significantly cell proliferation (data not shown).

In the presence of adult collagen, DDR2 phosphorylation was significantly higher in adult collagen when compared to the old one. We further show that downregulation of DDR2 expression and inhibition of its kinase function by nilotinib induced an increase in HT1080 cell proliferation to a level similar to that of the old one. To our knowledge, we show for the first time a differential DDR2 activation in adult and old collagen suggesting the involvement of DDR2 in the regulation of cell proliferation by collagen aging. DDR2 is well known to be activated by fibrillar type I collagen [15] and this property is crucial in the down-regulation of tumor cell proliferation by this receptor [22]. Interestingly, our group has recently observed detrimental changes in fibrillar type I collagen properties with aging $[6,17]$ that could explain the loss of DDR2 activation by old collagen resulting from impaired DDR2/collagen interactions.

The tyrosine phosphatase SHP-2, a specific downstream effector of DDR2 [29], is more phosphorylated in the presence of adult collagen when compared with the old one. This highly correlates with the differential activation of DDR2 observed between the two collagens. In addition, using nilotinib, we confirm that DDR2 kinase activity is required for SHP2 phosphorylation (Figure 8), as described in lung cancer expressing DDR2 with mutations in the kinase domain [29]. The phosphorylated Tyr-1007 of JAK2, which is necessary for its kinase activity [42] has been proved to be a target for SHP-2 [30]. Here, we show that the phosphorylation level of JAK2 Tyr-1007 was lower in adult collagen when compared to the old one. This suggests that DDR2-mediated SHP-2 activation is a critical step in the down-regulation of JAK2 activity and consequently in cell growth suppression.
We demonstrate that ERK1/2 phosphorylation, known to promote cell proliferation [32], is lower in the presence of adult collagen. ERK1/2 has been shown to phosphorylate $\mathrm{p} 21^{\mathrm{CIP} 1}$ which is subsequently exported from the nucleus and ubiquitinated before degradation in the proteasome [43]. Consistently, we find an overexpression of $\mathrm{p} 21^{\mathrm{CIP} 1}$ in the presence of adult collagen associated with a decrease in ERK1/2 phosphorylation. We also show that DDR2 inhibition in adult collagen induces an increase in ERK1/2 phosphorylation and downregulation of $\mathrm{p} 21^{\mathrm{CIP} 1}$. In addition, JAK2 inhibition in old collagen induces a decrease in ERK1/2 phosphorylation and an increase in p2 $1^{\mathrm{CIP} 1}$ expression. This establishes a link between the ERK1/2-p21 ${ }^{\mathrm{CIP} 1}$ and DDR2-JAK2 axes in the regulation of HT-1080 tumor cell growth.

In conclusion, we show in agreement with previously reported data $[5,41]$ that biologically aged type I collagen has the capacity to increase the proliferative behavior of human tumor cells in a $3 \mathrm{D}$ context. We identify for the first time DDR2 as a key matrix aging sensor responsible for the regulation of this process. As summarized in Figure 12, the regulation of cell proliferation by the collagen/DDR2 axis involves a differential activation of SHP-2, JAK2/ERK1/2 signaling pathways, and $\mathrm{p} 21^{\mathrm{CIP} 1}$ expression. In addition, our study suggests that the impact of matrix aging has to be taken into account when designing in-vitro experiments to understand cell/ECM interactions, and to evaluate their consequences on tumor cell responses. Such agedependent processes may also contribute to better address the higher proliferative tumors behavior observed for elderly patients [44, 45].

\section{MATERIALS AND METHODS}

\section{Cell lines}

The human fibrosarcoma cell line HT-1080 (CCL-121) and the human breast adenocarcinoma cell line MCF-7 (HTB-22) were purchased from the American Type Culture Collection (ATCC, Rockville, MD, USA). HT-1080 cells stably transfected with empty vector (HT-1080 Neo), human full length RAGE (HT-1080 Full RAGE) and dominant negative RAGE (HT-1080 DN RAGE) were obtained from Dr. Takeuchi A. (Kanazawa Medical University, Uchinada, Japan) [20]. All these cell lines were cultured in MEM with Earle salts and Glutamax I (Invitrogen, Cergy-pontoise, France) supplemented with $10 \%$ fetal bovine serum, (Invitrogen) and 1\% penicillinstreptomycin (Invitrogen). RAGE transfected HT-1080 cells were cultured in the presence of $750 \mu \mathrm{g} / \mathrm{mL} \mathrm{G} 418$ (Roche Applied Science, Mannheim, Germany). Cultures were maintained at $37^{\circ} \mathrm{C}$ in a humidified atmosphere containing $5 \% \mathrm{CO}_{2}(\mathrm{v} / \mathrm{v})$. Cells were routinely passaged 
at preconfluency using $0.05 \%$ trypsin, $0.53 \mathrm{mM}$ EDTA (Invitrogen) and screened for the absence of mycoplasma using PCR methods.

\section{Preparation and characterization of type I collagen}

Fibrillar and non-pepsinized collagen type I was extracted from tail tendons of 2 months (adult) and 2 years old (old) rats, and prepared as already described [46]. Spectrofluorimetric analysis was performed on adult and old collagen solubilized at $2 \mathrm{mg} / \mathrm{ml}$ in $18 \mathrm{mM}$ acetic acid $(\mathrm{v} / \mathrm{v})$ to detect AGEs-specific fluorescence using a spectrofluorimeter (Shimadzu model RF-500) at $\lambda_{\text {ex }}=380 \mathrm{~nm}$ and $\lambda_{\text {em }}=440 \mathrm{~nm}$. AGE-modified BSA was used as a standard. Pentosidine and CML concentrations were measured using LC/MS/MS. One mg of collagen was hydrolyzed at $110^{\circ} \mathrm{C}$ during 18 hours in the $6 \mathrm{M}$ $\mathrm{HCl}$, and hydrolysates were evaporated to dryness under nitrogen stream. Dried hydrolyzates were then resuspended in $100 \mu \mathrm{l}$ of $125 \mathrm{mM}$ ammonium formate, prior to LC-MS/MS analysis with a gradient composed of $5 \mathrm{mM}$ ammonium formate ( $\mathrm{pH}$ 2.9) as mobile phase A and $100 \%$ acetonitrile as mobile phase B. Detection was performed using an API4000 system (ABSciex, France) in positive-ion mode with an elestrospray ionisation (ESI) source. Cross-links quantification was performed by ion exchange chromatography (Hitachi L-8800). Collagens hydrolysates were prepared as described above. Dried hydrolyzates were then resuspended in 100 $\mu \mathrm{l}$ of a buffer composed of (lithium $13.86 \mathrm{mM}$, lithium citrate $55 \mathrm{mM}$, citric acid $207 \mathrm{mM}$, ethanol $6 \%(\mathrm{v} / \mathrm{v})$, thiodiglycol $1 \%(\mathrm{v} / \mathrm{v})) \mathrm{pH} 2.8$. The chromatography was performed according to the manufacturer's instructions. The two enzymatic cross-links hydroxylysylpyridinoline and lysylpyrodinoline were quantified and expressed as $\mu \mathrm{mol} / \mathrm{mol}$ collagen. Electrophoretic properties of aged collagen were estimated by $5 \%$ sodium dodecyl sulfatepolyacrylamide gel electrophoresis (SDS-PAGE), under denaturing conditions $\left(4 \mathrm{~min}\right.$ at $\left.90^{\circ} \mathrm{C}\right)$. Gels were stained with Coomassie Brillant Blue R250.

\section{D and 3D cell culture}

The effects of the aged type I collagen on HT- 1080 cell proliferation were studied using 24-well plates. For 2D cell culture, each well was coated by adding $250 \mu \mathrm{l}$ of native or modified collagens solubilized in $0.018 \mathrm{M}$ acetic acid at a concentration of $38 \mu \mathrm{g} / \mathrm{ml}$. Then, coated substrates were dried overnight at room temperature under sterile conditions and rinsed once in PBS (Invitrogen) before cell plating. HT-1080 cells were seeded on the coated surfaces at a concentration of $1.5 \times 10^{4}$ cells/well $(1$ $\mathrm{ml} /$ well). For $3 \mathrm{D}$ cell culture, $1.5 \times 10^{4} \mathrm{HT}-1080$ cells were resuspended in $100 \mu \mathrm{l}$ fetal bovine serum and mixed with a solution containing $100 \mu \mathrm{l}$ MEM 10X (Sigma-Aldrich, St. Quentin-Fallavier, France), $100 \mu \mathrm{l} \mathrm{NaHCO}_{3} 0.26 \mathrm{M}$, $100 \mu \mathrm{l} \mathrm{H} \mathrm{O}_{2}, 90 \mu \mathrm{l} \mathrm{NaOH} 0.1 \mathrm{M}, 10 \mu \mathrm{l}$ glutamine $200 \mathrm{mM}$ and $500 \mu \mathrm{l}$ collagen $3 \mathrm{mg} / \mathrm{ml}$. This solution was deposited in 24-well plates $(1 \mathrm{ml} /$ well $)$. After polymerization at $37^{\circ} \mathrm{C}$ during $10 \mathrm{~min}$, gels were recovered by $1 \mathrm{ml}$ MEM $10 \%$ foetal bovine serum and $3 \mathrm{D}$ cultures were incubated during 4 to 7 days. Then, medium recovering 3D cultures was eliminated, and gels were digested by collagenase $P$ at $3 \mathrm{mg} / \mathrm{ml}$ (Roche, Meylan, France), cell viability and density were determined by phase contrast microscopy. During these experiments, the covering culture medium was not renewed.

\section{Blocking antibody and pharmalogical inhibitors}

In some experiments, cells were treated with blocking antibodies or different pharmacological inhibitors. Blocking antibodies were preincubated with the cells during $30 \mathrm{~min}$ at room temperature, at the following concentration: $\beta 1$ integrin antibody $(10 \mu \mathrm{g} / \mathrm{ml}$, MAB2253Z, Millipore, St. Quentin en Yvelines, France). Pharmacological inhibitors were added in the gels at the indicated concentrations: U0126 $(5 \mu \mathrm{M}$, Promega, Charbonnière-les-bains, France), AG490 (10 $\mu \mathrm{M}$, Santa Cruz Biotechnology) and nilotinib (100 nM, Selleckchem, Souffelweyersheim, France). Cells were then embedded in collagen 3D matrices, as described above.

\section{siRNA transfections}

siRNA oligonucleotides were transfected in HT1080 cells with Lipofectamine RNAiMax (Invitrogen) according to the manufacturer's instructions. Pools of 3 target-specific 19-25 nucleotides DDR2 siRNA (sc39922) and $\beta 1$ integrin siRNA (sc-35674) were purchased from Santa Cruz Biotechnology, and were used at $50 \mathrm{nM}$. Negative control siRNA (1027310) was purchased from Qiagen (Courtaboeuf, France). Cells were allowed to grow 24 hours after transfection before use. DDR2 and $\beta 1$ integrin extinction were controlled by western blotting and RT-PCR respectively, then cells were seeded in type I collagen 3D matrices as described above.

\section{Western blotting}

Cells were lyzed with RadioImmunoPrecipitation Assay (RIPA) buffer (Thermo Fisher Scientific, Villebon sur Yvette, France). Cell lysates were clarified by centrifugation at $14000 \times \mathrm{g}$ at $4^{\circ} \mathrm{C}$ for $15 \mathrm{~min}$. For western blotting, proteins were separated by SDS-PAGE gels and transferred to a nitrocellulose membrane. Then, membranes were blocked with Tris buffered saline (TBS) (0.02 M Tris-HCl, $0.137 \mathrm{M} \mathrm{NaCl}, \mathrm{pH}$ 7.4) containing 
$0.1 \%$ Tween (TBS-T) and 5\% non-fat dry milk at room temperature during 1 hour and incubated overnight at $4^{\circ} \mathrm{C}$ with the following primary antibodies: anti-phosphoJAK2 (Santa Cruz Biotechnology), anti-GAPDH, antiDDR1, anti-phospho-SHP2, anti-SHP2, anti-JAK2, anti-phospho-ERK1/2, anti-ERK1/2, anti-p21 ${ }^{\mathrm{CIP} 1}$ (Cell signaling Technology, Saint Quentin Yvelines, France), anti-DDR2 (R\&D systems, Lille, France), anti-RAGE (GeneTex, Irvine, CA). Membranes were washed with TBS-T and incubated with the corresponding peroxidase conjugated secondary antibody at room temperature for 1 hour. Chemiluminescent detection was realized by using an ECL Prime Kit (GE Healthcare, Orsay, France).

\section{Immunoprecipitation}

HT-1080 cells were washed with DPBS and incubated overnight in serum-free media prior 6 hours of stimulation in adult and old type I collagen $3 \mathrm{D}$ matrices. Cells were then lysed with RIPA buffer, and cell lysates were clarified by centrifugation at $14000 \times$ $\mathrm{g}$ at $4^{\circ} \mathrm{C}$ for $15 \mathrm{~min}$. Then $300 \mu \mathrm{g}$ of whole-cell extracts was immunoprecipitated with anti-DDR2 (1:100, Santa Cruz Biotechnology) at $4^{\circ} \mathrm{C}$ for 12 hours and then bound to protein $\mathrm{G}$ agarose beads (GE Healthcare) and finally washed three times with TBS. The proteins were separated by SDS-PAGE, and the immunoprecipitates were blotted with anti-phosphotyrosine 4G10 antibodies (Millipore). The blots were then stripped using a stripping buffer (100 mM 2-mercaptoethanol, 2\% SDS, 63 mM Tris- $\mathrm{HCl}$ $\mathrm{pH}$ 6.8) and re-probed with anti-DDR2 (R\&D systems) antibody.

\section{Quantitative RT-PCR}

Cells were seeded in 6-well plates at a density of $1.5 \times 10^{4}$ cells/well. After 3 days, culture media were removed and the cells were washed two times with cold DPBS. Total RNA purification was performed with the RNeasy Mini Kit (Qiagen) and $1 \mu \mathrm{g}$ of RNA was converted to cDNA by reverse transcription using the Maxima First Strand cDNA Synthesis kit (Thermo Fisher Scientific), and a PCR MasterCycler ${ }^{\circledR}$ (Eppendorf, Montesson, France). Then real-time PCR was performed using a Maxima SYBR GREEN/ROX qPCR Master Mix (Thermo Fisher Scientific) on the Stratagene Mx3005P qPCR detection system (Agilent Technologies, Les Ulis, France). Polymerase chain reaction conditions were $15 \mathrm{~min}$ at $+95^{\circ} \mathrm{C}$, followed by 35 cycles each consisting of $15 \mathrm{~s}$ at $+95^{\circ} \mathrm{C}$ (denaturation) and $30 \mathrm{~s}$ at $+60^{\circ} \mathrm{C}$ (annealing/ extension). Results were standardized to the eEF1al gene expression by calculating $\Delta \mathrm{Ct}$ using the formula $\Delta \mathrm{Ct}=$ $\left(\mathrm{Ct}_{\text {gene of interest }}-\mathrm{Ct}_{\mathrm{eEF1A}}\right)$. Gene expression was represented as $2^{-\Delta \mathrm{Ct}}$. The forward primer for DDR1 transcript was 5'-TGCTCTCCAATCCAGCCTAC-3' and the reverse primer was 5'-ATTATGCCGAGGCTGACATT-3' with a $203 \mathrm{bp}$ product. The forward primer for DDR2 transcript was 5'-GCGCCATGCAGGAGGTCTAG -3 ' and the reverse primer was 5'-CCACTCTCATACACACATTCA-3' with a $230 \mathrm{bp}$ product. The forward primer for eEF1A transcript was 5'-CTGGAGCCAAGTGCTAACATGCC-3' and the reverse primer was 5'-CCGGGTTTGAGAACACCAGTC-3' with a 221 bp product. The forward primer for RAGE transcript was 5'-AAACATCACAGCCCGGATTG-3' and the reverse primer was 5'- TCCGGCCTGTGTTCAGTTTCC-3' with a $101 \mathrm{bp}$ product. To verify $\beta 1$ integrin silencing, a classical PCR amplification was carried out. The forward primer for $\beta 1$ integrin transcript was 5'-TGCGAGTGTGGTGTCTGTAA-3' and the reverse primer was 5'-AGGCTCTGCACTGAACACAT-3' with a $118 \mathrm{bp}$ product. The forward primer for actin transcript was 5'-GTGTGACGTGGACATCCGC-3' and the reverse primer was 5'-CTGCATCCTGTCGGCAATG-3' with a $91 \mathrm{bp}$ product. The resulting PCR products were visualized by ultraviolet after staining with ethidium bromide.

\section{Statistical analysis}

Data are presented as mean \pm standard error of the mean (SEM). The values were analyzed with Student's t-test. p values lower than 0.05 were considered as significant. $* p<0.05 ; * * p<0.01$; ***p $<0.001$. Electrophoretic images were analyzed with ImageJ software.

\section{ACKNOWLEDGMENTS}

We would like to acknowledge the help of Dr. Saltel F. for the critical review of the manuscript. We thank Pr. Sockalingum G.D. and Ricord S. for the English revision of the manuscript. We are grateful to Dr. Hammerman P.S. for the DDR2 gatekeeper construct. We thank Dr. Takeuchi A. for HT-1080 cells expressing dominant negative and wild-type RAGE. Finally, we thank Dr. Rio M.C and Dr. Trent J.C. for the 293 T and the A204 cells respectively.

\section{GRANT SUPPORT}

This work was supported by grants from Ligue Contre le Cancer 2012 and 2016 (CCIR Grand-Est) and FEDER/Emergence CELLnanoFLUO Program 2012 (Région Champagne-Ardenne). C. Saby is recipient of a doctoral fellowship from the French Ministry of Higher Education and Research. 


\section{CONFLICTS OF INTEREST}

There is no conflict of interest.

\section{REFERENCES}

1. Quail DF and Joyce JA. Microenvironmental regulation of tumor progression and metastasis. Nat Med. 2013; 19:14231437.

2. Wolf K, Alexander S, Schacht V, Coussens LM, von Andrian UH, van Rheenen J, Deryugina E and Friedl P. Collagen-based cell migration models in vitro and in vivo. Semin Cell Dev Biol. 2009; 20:931-941.

3. Bailey AJ, Paul RG and Knott L. Mechanisms of maturation and ageing of collagen. Mech Ageing Dev. 1998; 106:1-56.

4. Logsdon CD, Fuentes MK, Huang EH and Arumugam T. RAGE and RAGE ligands in cancer. Curr Mol Med. 2007; 7:777-789.

5. Bartling B, Desole M, Rohrbach S, Silber RE and Simm A. Age-associated changes of extracellular matrix collagen impair lung cancer cell migration. FASEB J. 2009; 23:15101520 .

6. Ait-Belkacem D, Guilbert M, Roche M, Duboisset J, Ferrand P, Sockalingum G, Jeannesson P and Brasselet S. Microscopic structural study of collagen aging in isolated fibrils using polarized second harmonic generation. J Biomed Opt. 2012; 17:080506-080501.

7. Maquoi E, Assent D, Detilleux J, Pequeux C, Foidart JM and Noel A. MT1-MMP protects breast carcinoma cells against type I collagen-induced apoptosis. Oncogene. 2012; 31:480-493.

8. Cox TR, Bird D, Baker AM, Barker HE, Ho MW, Lang $\mathrm{G}$ and Erler JT. LOX-mediated collagen crosslinking is responsible for fibrosis-enhanced metastasis. Cancer Res. 2013; 73:1721-1732.

9. Levental KR, Yu H, Kass L, Lakins JN, Egeblad M, Erler JT, Fong SF, Csiszar K, Giaccia A, Weninger W, Yamauchi M, Gasser DL and Weaver VM. Matrix crosslinking forces tumor progression by enhancing integrin signaling. Cell. 2009; 139:891-906.

10. Humphries JD, Byron A and Humphries MJ. Integrin ligands at a glance. J Cell Sci. 2006; 119:3901-3903.

11. Leitinger B. Discoidin domain receptor functions in physiological and pathological conditions. Int Rev Cell Mol Biol. 2014; 310:39-87.

12. Knight CG, Morton LF, Peachey AR, Tuckwell DS, Farndale RW and Barnes MJ. The collagen-binding A-domains of integrins alpha(1)beta(1) and alpha(2) beta(1) recognize the same specific amino acid sequence, GFOGER, in native (triple-helical) collagens. J Biol Chem. 2000; 275:35-40.

13. Carafoli $\mathrm{F}$ and Hohenester E. Collagen recognition and transmembrane signalling by discoidin domain receptors. Biochim Biophys Acta. 2013; 1834:2187-2194.
14. Wolf-Yadlin A, Hautaniemi S, Lauffenburger DA and White FM. Multiple reaction monitoring for robust quantitative proteomic analysis of cellular signaling networks. Proc Natl Acad Sci U S A. 2007; 104:5860-5865.

15. Vogel W, Gish GD, Alves F and Pawson T. The discoidin domain receptor tyrosine kinases are activated by collagen. Mol Cell. 1997; 1:13-23.

16. Dammann P, Sell DR, Begall S, Strauch C and Monnier VM. Advanced glycation end-products as markers of aging and longevity in the long-lived Ansell's mole-rat (Fukomys anselli). J Gerontol A Biol Sci Med Sci. 2012; 67:573-583.

17. Wilson SL, Guilbert M, Sule-Suso J, Torbet J, Jeannesson P, Sockalingum GD and Yang Y. A microscopic and macroscopic study of aging collagen on its molecular structure, mechanical properties, and cellular response. FASEB J. 2014; 28:14-25.

18. Jiang ST, Liao KK, Liao MC and Tang MJ. Age effect of type I collagen on morphogenesis of Mardin-Darby canine kidney cells. Kidney Int. 2000; 57:1539-1548.

19. Abe R, Shimizu T, Sugawara H, Watanabe H, Nakamura H, Choei H, Sasaki N, Yamagishi S, Takeuchi M and Shimizu $\mathrm{H}$. Regulation of human melanoma growth and metastasis by AGE-AGE receptor interactions. J Invest Dermatol. 2004; 122:461-467.

20. Takeuchi A, Yamamoto Y, Munesue S, Harashima A, Watanabe T, Yonekura H, Yamamoto H and Tsuchiya H. Low molecular weight heparin suppresses receptor for advanced glycation end products-mediated expression of malignant phenotype in human fibrosarcoma cells. Cancer Sci. 2013; 104:740-749.

21. Leitinger B. Transmembrane collagen receptors. Annu Rev Cell Dev Biol. 2011; 27:265-290.

22. Wall SJ, Werner E, Werb Z and DeClerck YA. Discoidin domain receptor 2 mediates tumor cell cycle arrest induced by fibrillar collagen. J Biol Chem. 2005; 280:40187-40194.

23. Millerot-Serrurot E, Guilbert M, Fourre N, Witkowski W, Said G, Van Gulick L, Terryn C, Zahm JM, Garnotel R and Jeannesson P. 3D collagen type I matrix inhibits the antimigratory effect of doxorubicin. Cancer Cell Int. 2010; 10:26.

24. Ren T, Zhang W, Liu X, Zhao H, Zhang J, Zhang J, Li X, Zhang Y, Bu X, Shi M, Yao L and Su J. Discoidin domain receptor 2 (DDR2) promotes breast cancer cell metastasis and the mechanism implicates epithelial-mesenchymal transition programme under hypoxia. J Pathol. 2014; 234:526-537.

25. Shitomi Y, Thogersen IB, Ito N, Leitinger B, Enghild JJ and Itoh Y. ADAM10 controls collagen signaling and cell migration on collagen by shedding the ectodomain of discoidin domain receptor 1 (DDR1). Mol Biol Cell. 2015; 26:659-673.

26. Day E, Waters B, Spiegel K, Alnadaf T, Manley PW, Buchdunger E, Walker $\mathrm{C}$ and Jarai G. Inhibition of collagen-induced discoidin domain receptor 1 and 2 
activation by imatinib, nilotinib and dasatinib. Eur $\mathrm{J}$ Pharmacol. 2008; 599:44-53.

27. Beauchamp EM, Woods BA, Dulak AM, Tan L, Xu C, Gray NS, Bass AJ, Wong KK, Meyerson M and Hammerman PS. Acquired resistance to dasatinib in lung cancer cell lines conferred by DDR2 gatekeeper mutation and NF1 loss. Mol Cancer Ther. 2014; 13:475-482.

28. Hammerman PS, Sos ML, Ramos AH, Xu C, Dutt A, Zhou W, Brace LE, Woods BA, Lin W, Zhang J, Deng X, Lim SM, Heynck S, Peifer M, Simard JR, Lawrence MS, et al. Mutations in the DDR2 kinase gene identify a novel therapeutic target in squamous cell lung cancer. Cancer Discov. 2011; 1:78-89.

29. Iwai LK, Payne LS, Luczynski MT, Chang F, Xu H, Clinton RW, Paul A, Esposito EA, Gridley S, Leitinger B, Naegle KM and Huang PH. Phosphoproteomics of collagen receptor networks reveals SHP-2 phosphorylation downstream of wild-type DDR2 and its lung cancer mutants. Biochem J. 2013; 454:501-513.

30. Xu D and Qu CK. Protein tyrosine phosphatases in the JAK/ STAT pathway. Front Biosci. 2008; 13:4925-4932.

31. Neradugomma NK, Subramaniam D, Tawfik OW, Goffin V, Kumar TR, Jensen RA and Anant S. Prolactin signaling enhances colon cancer stemness by modulating Notch signaling in a Jak2-STAT3/ERK manner. Carcinogenesis. 2014; 35:795-806.

32. Mebratu $Y$ and Tesfaigzi $Y$. How ERK1/2 activation controls cell proliferation and cell death: Is subcellular localization the answer? Cell Cycle. 2009; 8:1168-1175.

33. Park JI. Growth arrest signaling of the Raf/MEK/ERK pathway in cancer. Front Biol (Beijing). 2014; 9:95-103.

34. Egeblad M, Rasch MG and Weaver VM. Dynamic interplay between the collagen scaffold and tumor evolution. Curr Opin Cell Biol. 2010; 22:697-706.

35. Henriet P, Zhong ZD, Brooks PC, Weinberg KI and DeClerck YA. Contact with fibrillar collagen inhibits melanoma cell proliferation by up-regulating p27KIP1. Proc Natl Acad Sci U S A. 2000; 97:10026-10031.

36. Wall SJ, Zhong ZD and DeClerck YA. The cyclindependent kinase inhibitors p15INK4B and p21CIP1 are critical regulators of fibrillar collagen-induced tumor cell cycle arrest. J Biol Chem. 2007; 282:24471-24476.
37. Hotary KB, Allen ED, Brooks PC, Datta NS, Long MW and Weiss SJ. Membrane type I matrix metalloproteinase usurps tumor growth control imposed by the three-dimensional extracellular matrix. Cell. 2003; 114:33-45.

38. Malik R, Lelkes PI and Cukierman E. Biomechanical and biochemical remodeling of stromal extracellular matrix in cancer. Trends Biotechnol. 2015; 33:230-236.

39. Yamada KM and Cukierman E. Modeling tissue morphogenesis and cancer in 3D. Cell. 2007; 130:601-610.

40. Assent D, Bourgot I, Hennuy B, Geurts P, Noel A, Foidart JM and Maquoi E. A Membrane-Type-1 Matrix Metalloproteinase (MT1-MMP) - Discoidin Domain Receptor 1 Axis Regulates Collagen-Induced Apoptosis in Breast Cancer Cells. PLoS One. 2015; 10:e0116006.

41. Damodarasamy M, Vernon RB, Chan CK, Plymate SR, Wight TN and Reed MJ. Hyaluronan in aged collagen matrix increases prostate epithelial cell proliferation. In Vitro Cell Dev Biol Anim. 2015; 51:50-58.

42. Feng J, Witthuhn BA, Matsuda T, Kohlhuber F, Kerr IM and Ihle JN. Activation of Jak2 catalytic activity requires phosphorylation of Y1007 in the kinase activation loop. Mol Cell Biol. 1997; 17:2497-2501.

43. Hwang CY, Lee C and Kwon KS. Extracellular signalregulated kinase 2-dependent phosphorylation induces cytoplasmic localization and degradation of p21Cip1. Mol Cell Biol. 2009; 29:3379-3389.

44. Liotta LA and Kohn EC. The microenvironment of the tumour-host interface. Nature. 2001; 411:375-379.

45. de Magalhaes JP. How ageing processes influence cancer. Nat Rev Cancer. 2013; 13:357-365.

46. Garnotel R, Rittie L, Poitevin S, Monboisse JC, Nguyen P, Potron G, Maquart FX, Randoux A and Gillery P. Human blood monocytes interact with type I collagen through alpha $\mathrm{x}$ beta 2 integrin (CD11c-CD18, gp150-95). J Immunol. 2000; 164:5928-5934. 